Chapter 9

\title{
Persistence of HIV-Associated Neurocognitive Disorders in the Era of Antiretroviral Therapy
}

\author{
Jennifer M. King, Brigid K. Jensen, \\ Patrick J. Gannon and Cagla Akay \\ Additional information is available at the end of the chapter \\ http://dx.doi.org/10.5772/52683
}

\section{Introduction}

HIV-Associated Neurocognitive Disorders (HAND) is a serious menifestation of HIV infection in the central nervous system (CNS), and encompassess a wide spectrum of cognitive, behavioral, and motor deficits [1-3]. While the implementation of combination antiretroviral therapy (ART) has dramatically increased the life expectancy and led to significant improvements in the clinical presentation and progression of HAND, an estimated $50 \%$ of HIV-infected patientscontinue to suffer from implications of HAND in the ART era, with as much as $20 \%$ of these exhibiting symptoms of HIV-associated dementia (HAD), the most severe form of HAND [3-6]. The brain regions affected in patients with HAND has changed in the ART era in parallel to the changes observed in the clinical picture; a more subtle and insidious cortical damage mainly in the hippocampus and the temporal cortex is observed, in contrast to the overt subcortical damage seen before ART [7-10]. The underlying causes of these changes are not fully elucidated; however, examination of the post-mortem tissue reveals the persistence of synaptic and dendritic damage in the affected brain regions [3, 11]. Emerging evidence suggests that controlling viral replication in the periphery or in the CNS may not be sufficient to control the underlying neuropathological processes that culminate in the development of HAND. The impact of HAND on the quality of life, adherence to drug regimens, and co-morbidities especially in an aging HIV population with decreased cognitive reserves, is of major concern. In this chapter, we will examine the major factors that continue to impact the CNS of HIV-infected individuals, and introduce new challenges in the successful treatment of HAND. 


\section{Clinical presentation and neuropathology of HAND}

According to the diagnostic criteria established for the assessment of neurocognitive impairment in HIV-infected individuals, the neurological deficits in HAND patients are divided into three diagnostic groups. This classification is based on the neuropsychological evaluation of multiple cognitive domains, including simple motor skills or sensory perceptual ability, complex perceptual motor skills, attention and working memory, learning and memory recall, verbal and language, abstraction and executive function. Asymptomatic neurocognitive impairment (ANI) is defined as acquired impairment in at least two cognitive domains without a decline in activities of daily living (ADL), while mild to moderate neurocognitive impairment that affects ADL is termed minor neurocognitive disorder (MND). Moderate to severe impairment in two or more domains with marked impact on ADL is defined as HAD. Additionally, behavioral and emotional problems such as depression, psychosis and anxiety are commonly observed in HAND patients. Since the multi-drug regimens that form the basis of ART have become the mainstay of HIV, the clinical presentation and the course of HAND have become more unpredictable. The severity of deficits appears to fluctuate over time during the course of infection: some patients may experience continuing decline in cognitive abilities, while others may recover from HAD and exhibit only minor deficits for the remainder of the disease. While clinical studies clearly establish that suppression of viral replication below the level of detection is paramount to a more favorable outcome, the clinical course of HAND, once diagnosed, cannot be predicted successfully in most patients.

While microglial nodules, multinucleated giant cells and astrogliosis, all of which are associated with HIV-induced inflammatory changes, are not as frequently found in post-mortem HAND brain tissue after ART, dendritic and synaptic damage still persist [12-16]. For example, several studies have reported the presence of deoxynucleotidyltransferase-mediated dUTP nick-end labeling (TUNEL)-positive cells, DNA laddering and structural changes with electron microscopy $[17,18]$. Importantly, these markers of neuronal death correlate with activation of immune cell populations suggesting that the inflammatory mediators secreted by these cells may play a role in initiating the death cascades [1, 19]. Given the chronic nature of the HIV infection in the ART era, co-existing conditions which can activate immune responses and precipitate a neuroinflammatory environment independent of infection are likely to contribute to the development of persistent neuropathology, and need to be addressed for a more efficient clinical approach and more favorable outcomes. Foremost, it is necessary to examine the mechanisms of neuronal injury in order to successfully expound on the contribution of confounding factors on the persistence of HAND.

The two major cell types targeted by HIV are $\mathrm{CD}^{+}{ }^{+} \mathrm{T}$ cells and the cells of monocyte/macrophage lineage. HIV infection of the $\mathrm{CD}^{+} \mathrm{T}$ cells ends in the selective loss of this cell population, leading to severe immunodeficiency [20]. More relevant to HAND, HIV also targets monocytes early during infection [20]. In the healthy brain, the BBB and the blood-cerebrospinal fluid barriers are the first lines of defense against invading pathogens; however, HIV can circumvent these barriers and enter the CNS within infected monocytes [21, 22]. According to this model, supported by a multitude of in vitro and in vivo studies, the infected mon- 
ocytes differentiate into macrophages, and constitute the viral reservoirs in the CNS [23-26]. Moreover, these cells release a variety of molecules, some of them known neurotoxins, leading to the eventual neuronal damage and dysfunction observed in HAND. Importantly, unlike other cell types that readily undergo replication, neurons in their post-mitotic state are more vulnerable to immune cell damage which can disrupt critical neuronal functions. Additionally, recent focus in efforts towards a cure in HIV is purging the virus from its reservoirs, by reactivating pro-viral DNA [27-31]. Thus, it is crucial to examine the impact of HIV infection on immune cells for a better understanding of the neuropathology of HAND, and for the development of successful paradigms for HIV reactivation and purging.

\section{The immunology of HAND}

\subsection{Initiation of immune response in the CNS}

HIV initially enters helper T lymphocytes and monocytes in the periphery via viral glycoproteins, gp120 and gp41, which are part of the HIV envelope [32]. These glycoproteins engage with the CD4 on the host cell membrane; however, this fusion step requires the presence of a chemokine co-receptor, $\mathrm{C}-\mathrm{X}-\mathrm{C}$ chemokine receptor type 4 (CXCR4) in lymphocytes,orC-C chemokine type 5 (CCR5) / C-C chemokine type 3 (CCR3) in macrophages [32, 33]. Of all the cell types in the brain, only macrophages and microglia express CD4 antigen, are commonly infected by HIV, and are capable of productive infection. There is very limited evidence for HIV infection of the glial cells, which if present, has not been conclusively shown as being productive [34]. More importantly, HIV cannot infect neurons as these cells lack CD4 co-receptors.

The CNS of a healthy adult human has a relatively low presence of cellular components of the immune system $[35,36]$. The CNS presents the immune system with unique problems with trafficking of immune cells and the recognition of foreign antigen when present. First, the BBB constitutes a physical barrier for the entry of cells and macromolecules from the periphery into the CNS. Additionally, there is minimal expression of major histocompatibility class II (MHC class II) molecules and an absence of professional antigen presenting cells such as dendritic cells, all of which are required for antigen presentation and adaptive immune response activation. However, it has been extensively shown that brain derived factors act to suppress or counter-regulate the actions of pro-inflammatory mediators in the CNS where immune surveillance is not sufficient. For example, transforming growth factor- $\beta$ (TGF- $\beta$ ) has the ability to inhibit the activation of macrophages, T lymphocytes, and natural killer (NK) cells, and has been shown to possess neuroprotective capabilities [37-41]. Interestingly, increased TGF- $\beta$ protein levels are reported in the frontal cortex of HAD patients, and elevated TGF- $\beta$ immunoreactivity has been detected in reactive astrocytes and mononuclear cells of the white matter in HIV-infected CNS $[42,43]$. Similar roles have been proposed for BDNF, NT-3, and NGF, among others, during HIV infection in the CNS [44, 45]. 
In the initial stages of HIV infection, the number of CD4+T cells decreases as a consequence of uncontrolled viral replication. While the impact of primary HIV infection on specific CD8 ${ }^{+}$ $\mathrm{T}$ cell subpopulations is not clear, there is an overall expansion of this cell population [46]. In this environment, infected monocytes can enter the CNS, establish and maintain productive infection, and HAND becomes clinically manifest. Perivascular macrophages are replenished throughout life by the migration of circulating monocytes to the brain, a process enhanced in an inflammatory environment [47]. Several studies have shown that the number of activated macrophages, rather than the viral load,correlates best with the axonal damage and synaptic loss observed in the HAND brain [11, 14, 48, 49]. In addition, indirect markers of macrophage activation, such as neopterin and $\beta 2$-microglobulin, are elevated in the CSF of HAND patients [50-52]. Further, soluble factors that are known to be released by macrophages and glia, such as quinolinic acid, tumor necrosis factor- $\alpha$ (TNF- $\alpha$ ), reactive oxygen species (ROS), and cytokines such as CXCL12 (stromal cell-derived factor-1, SDF-1), CCL2 (monocyte chemotactic protein-1, MCP-1), and interleukin-6 (IL-6), are also elevated in the CSF of HAND patients [53-57]. These findings reinforce the model which proposes monocyte-derived macrophages and microglia as major instigators of the neuropathological processes in the course of disease development in HAND.

It should be noted that viral proteins such as gp120 and transactivator of transcription (Tat) can directly activate uninfected macrophages [58-62]. Additionally, one mechanism of injury that is proposed to account for neuronal damage in the absence of neuronal infection by HIV involves direct neurotoxicity by these viral proteins. Several in vitro studies have shown that these viral proteins that are released and/or shed by the infected macrophages/microglia can induce direct synaptic and neuronal damage [63-65]. However, the indicators of neuroinflammation continue to persist despite successful suppression of replication in the CSF to levels below the limit of detection with ART, suggesting that other, less direct mechanisms of injury might be major contributors to the underlying neuropathology.

\subsection{The role of cytokines and chemokines in HAND neuropathology}

A number of indirect mechanisms for the pathogenesis of HAND have been proposed $[1,25$, 66]. These mechanisms are not mutually exclusive, and may be synergistic based on the common background of macrophage activation and release of cytokines and chemokines.As a protective measure to suppress viral production, macrophages are responsible for the production of inflammatory mediators including TNF- $\alpha$, IL (interleukin)-1, interferon- $\alpha$ (IFN- $\alpha$ ) and nitric oxide synthase (NOS) [33, 59]. However, the release of these pro-inflammatory cytokines can activate the uninfected macrophages, and can induce the migration of leukocytes into the CNS [62]. For example, in HIV-1 transgenic (Tg) rats, elevated levels of IL-1 $\beta$ and TNF- $\alpha$ and increased expression of arachidonic acid cascade enzymes have been implicated in neuronal damage and cognitive and behavioral impairment [67]. A recent study indicates that similar changes could contribute to cognitive impairment in HIV-infected patients despite an effective ART [68]. In vivo studies suggest that the progression of HAND may be predicted by high concentrations of TNF- $\alpha$ in plasma, and polymorphisms in the TNF- $\alpha$ promoter are associated with HAND to a degree $[69,70]$. Interestingly, functional $e x-$ 
vivo studies have shown that the macrophages and B-lymphocytes isolated from HIV-infected patients are activated despite viral suppression by ART [71]. Further, in vitro experiments show that HIV reactivation can be achieved by cytokine and chemokine stimulation [30, 33]. These findings are especially important in light of recent concerns regarding viral latency and its contribution to the persistence of HAND [29].

In the CNS,chemoattractant cytokines, or chemokines have been demonstrated as essential factors in neuroinflammation and related neuronal injury and loss through their regulation of inflammatory responses. Post-mortem studies have revealed up-regulation of chemokines and chemokine receptors in the brains of patients with HAND [25, 26, 56, 72-75]. The bestcharacterized chemokines up-regulated in HAND are the $\beta$-chemokines CCL2, CCL5, and CX3CL1, and the alpha chemokine CXCL12. For example, the levels of one of the more potent chemokines, CCL2 correlate with the likelihood and severity of HAND [76, 77]. In addition, an intriguing regulatory role for the chemokine CCR5 was demonstrated that its activation led to cell death via caspase- 3 mediated apoptosis in a neuroblastoma cell line [78]. Further, induction of apoptosis has also been reported with CXCL12 in primary neuroglial cultures in the absence of the HIV viral protein gp120. However, results from several recent studies suggest that the changes in the expression of these chemokines may indicate neuroprotective efforts in response to the neuroinflammatory environment [79]. Further studies are needed to dissect the roles of chemokines in HAND pathogenesis, as they take part in a crucial phase in immune responses, and provide attractive targets for modulation in resolving HAND persistence.

The mechanisms by which the neuroinflammatory environment eventually ends in damage to the neurons are not precisely known; however, several mechanisms are likely candidates. Studies suggest that the neuronal damageis a result of indirect effects of viral proteins as well as inflammatory mediators $[1,66]$. Gp120 and Tat are reported to induce neuronal apoptosis by activating death-associated proteases, caspases, specifically caspase- 3 in in vitro and in vivo disease models [80]. Another mechanism proposes a role for excitotoxicity secondary to impaired glutamate reuptake by astrocytes which are overwhelmed by pro-inflammatory factors [81]. The well-defined cascade of excitotoxic injury includes excess $\mathrm{Ca}^{2+}$ influx into the neuronal cytoplasm. Several downstream events secondary to such increases in $\mathrm{Ca}^{2+}$ such as excess free radical production and oxidative stress, and the activation of $\mathrm{Ca}^{2+}-$ dependent death proteases, calpains and caspases, will be detrimental to neurons, especially in an environment with inadequate glial support and ongoing inflammation due to immune cell activation $[1,66]$.

\subsection{Neuroinflammation in HAND}

The persistence of immune activation in the CNS and the peripheral nervous system (PNS) of HIV-infected individuals in the ART era is supported by several lines of evidence. The relatively low levels of HIV RNA in the presence of widespread neuropathological changes in the CNS and PNS of HAND patients, and the lack of evidence of HIV infection of neuronal cells in vivo and in vitro hint at the possibility of chronic immune activation as a factor in the persistence of HAND. Recent clinical evidence shows that ART reduces intrathecal im- 
munoactivation in treated patients; however, a significant percentage of patients continue to exhibit signs of ongoing inflammation [49, 50, 82, 83]. Further, even after successful reduction of HIV RNA levels below the limit of detection for several years, patients present with increased levels of inflammatory markers such as CSF neopterin and intrathecal IgG [52]. It is thus apparent that ART is not sufficient to prevent or control HAND. One major factor to consider in addressing this failure is that ART may not be efficient and/or sufficient in controlling the inflammatory cascade triggered by HIV infection.

Once HIV replication is established in the CNS, the initial chemotactic and inflammatory factor production leads to further recruitment and activation of monocytes/macrophages, creating a perpetual neuroinflammatory environment. The phenomenon of monocyte/ macrophage recruitment can be explained by a "push and pull" mechanism [47]. Two key chemokines that play a role in the recruitment, or "pull", of monocytes are CCL2 and fractalkine (CXCL1).CCL2 is considered to be the more critical factor involved in the infiltration of monocytes and lymphocytes across the BBB in the HAND brain [79]. Multiple cell types of the CNS have been shown to produce CCL2 in models of inflammation, in which CCL2 is a part of a signaling mechanism for recruitment of monocytes/macrophages from the periphery. For example, leukocyte infiltration into the brain parenchyma has been demonstrated upon pertussis toxin challenge in CCL2 transgenic mice [84]. More importantly, HIVinfected leukocyte transmigration across BBB is dependent on CCL2 in an in vitro model of disease [85]. Further, CCL2 has been shown to directly damage the endothelial cell junctions of the BBB [86]. These findings clearly indicate a significant role for CCL2 in the "pull" of monocyte/macrophages across the BBB in HAND. Interestingly, CCL2 levels remain elevated in the CSF of HAND patients on ART, implicating that ongoing trafficking might be occurring despite viral suppression, and warrants further investigations into the persistence of HAND in the era of ART [83].

The "push" aspect of the monocyte/macrophage recruitment involves the expansion in peripheral blood neuroinvasive monocyte population. It has been shown that individuals with HAND exhibit an expanded population of $\mathrm{CD}_{14}^{+}$peripheral blood monocytes that co-express CD16, which is considered a more mature population [21]. These CD14 ${ }^{+} / \mathrm{CD}_{16}{ }^{+}$monocytes are preferentially susceptible to infection, and can serve as a reservoir harboring proviral DNA. The entry of monocytes into the brain plays a key role in initiating the series of events that lead to HAND, and although antiretrovirals hinder viral replication, they may have minimal effects on the continued transmigration of monocytes into the brain. One study showed that a single exposure of the CNS to the neurotoxic viral protein Tat led to the infiltration of peripheral blood monocytes and resulted in prolonged disruption of CNS function [87]. Thus, continuous and efficient viral suppression in the periphery is critical in achieving suppressed inflammation in the CNS, and is of prime importance in the fight against HAND.

While macrophages and microglia play primary roles in HIV infection in the CNS, other glial cells also contribute to the neuroinflammation and neurotoxicity in the HAND brain. One important cell type that needs to be mentioned in the neuroinflamatory processes in HAND is the astrocytic cell population. As the most abundant cells in the CNS, astrocytes 
provide neurotrophic support, and are involved in repair processes for neurons. Further, astrocytes are physiological regulators of microglial and macrophage inflammatory responses, and indirectly modulate neuronal survival through reduction of the macrophage inflammatory response. However, their dysfunction, as a result of HIV infection, will lead to the dysregulation of the local cytokine/chemokine balance. Evidence has shown that astrocytes are key mediators in the regulation of microglial function and its influence on the onset and the progression of HAND [55, 88]. Viral proteins gp120, and Tat both activate astrocytes to produce pro-inflammatory cytokines TNF- $\alpha$, IL- 6 , and IL-1 $\beta$ as well as the pro-inflammatory chemokines CCL2 and CXCL10 [34, 55, 89-91]. The contribution of these pro-inflammatory mediators by astrocytes as well as the release of pro-inflammatory cytokines IL-1 $\beta$ and TNF$\alpha$ by microglia and macrophage will only exacerbate the inflammatory environment in the HIV-infected CNS.

Although the pathogenic mechanisms of HAND are likely to be multifactorial (Table 1), cellular activation with the initiation and persistence of the immune system in the CNS play a pivotal role in this disease progression. Continued CNS inflammation is an essential factor in many neurodegenerative diseases and HIV infection induces a cascade of inappropriate immune responses in the CNS. The initial immunological response has protective intentions through macrophage activation, but with persistent infection, the inflammatory response becomes toxic to the neurons through the production of pro-inflammatory cytokines and chemokines. Further, the decreased viral load in the CNS is accompanied by persistent microglial activation and inflammation. Ineffective drug penetrance into the CNS, which continues to be a challenge, can initiate the development of resistance to ART via permitting mutations to the virus which allows the CNS to become a reservoir for the infection. As HIV-infected macrophages are shown to be resistant to apoptosis, this will end in exacerbating the virus reservoir in the CNS.

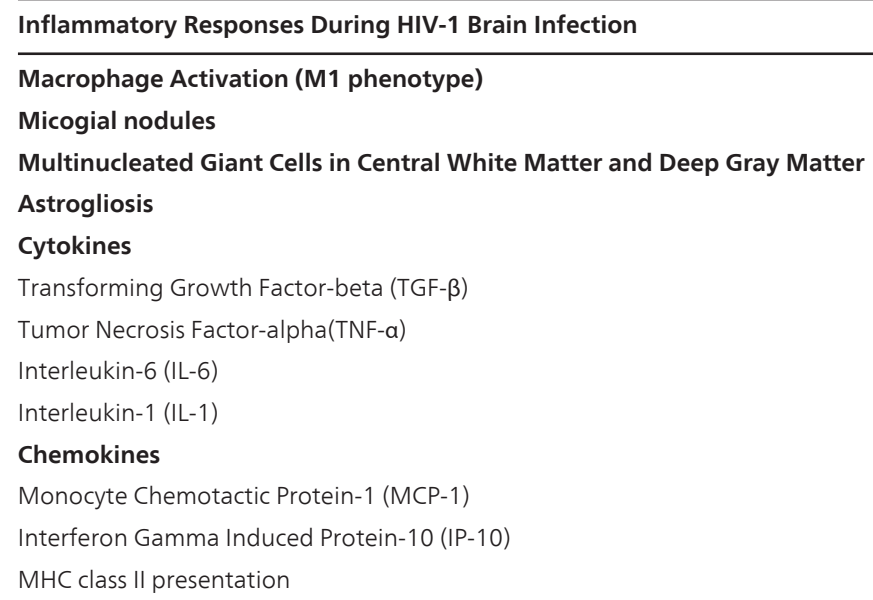

Table 1. Pathological and laboratory evidence for immune activation in the CNS after HIV infection. 
It should also be noted that the impact of HIV infection in the peripheral tissue will ultimately impact the immune responses in the CNS. Thus, co-morbidities such as co-infections, substance abuse, malignancies and antiretroviral drug toxicities, as well as general inflammatory processes in the periphery, such as oxidative stress should be taken into account when assessing the relationships between immune responses and the neuropathological processes occurring in the HAND brain. This approach will provide more efficient tools, and will have a greater impact on resolving the persistence of HAND.

\section{Oxidative stress in neurodegenerative diseases}

Oxidative stress is a shared pathological finding in a myriad of neurodegenerative diseases including Alzheimer Disease, Parkinson Disease, Multiple Sclerosis (MS), Amyotrophic Lateral Sclerosis (ALS), and HAND [92, 93]. While it is clear that chronic oxidative stress which will overwhelm the protective capacities of the cellular endogenous antioxidant responses may be responsible in part for the neuronal death occurring in these conditions, in many neurodegenerative diseases it is difficult to ascertain whether oxidative stress is the causative factor for disease pathology and progression, or rather a resultant downstream event of other cellular dysfunctions [92-95]. Nonetheless, in HAND, several lines of evidence suggest that both HIV and antiretroviral compounds may result in oxidative and nitrosative stress in the periphery and in the CNS [96-102]. Deficits in total antioxidant levels and increases in the markers for oxidative stress are still observed in individuals on stable ART regimens with undetectable viral titers, necessitating the need for adjunctive therapies to ameliorate this imbalance [103, 104]. As has been suggested in a variety of neurodegenerative conditions, antioxidant supplementation or upregulation of the endogenous antioxidant response in cells of the CNS may ameliorate the neuronal damage and death in HAND [1, 93, 94, 105].

\subsection{Oxidative stress in the era of ART}

The evidence of disrupted antioxidant balance and oxidative stress represent a continued concern for HIV-infected individuals even when virus is successfully controlled by ART [102]. To understand the magnitude and implications of this problem, it is important to understand the initial disruptions to the antioxidant system that were observed in infected individuals, and determine whether ART contributed to the resolution or the exacerbation of these problems.

Oxidative stress prior to ART:As early as 1988, while researchers were just beginning to understand the HIV virus, Sönnerborg and colleagues determined that plasma levels of malondialdehyde in adults with HIV infection were elevated up to $30 \%$ when compared with controls [106]. Malondialdehyde is the breakdown product of polyunsaturated lipids by reactive oxygen species, and is a mainstay in terms of a biological marker for measuring the relative levels of lipid peroxidation and oxidative stress in individuals [107]. A multitude of studies followed, showing significant increases in the levels of free radicals, hydroperoxides, hydroxynoneal, and oxidation of thiols in infected individuals, and confirming that malon- 
dialdehyde is increased significantly in infected adults, as well as children [108-118]. The metabolic synthesis of lipids is closely tied to the oxidative state of the cell and the lipids residing in the cell membrane, as certain enzymes such as sphingomyelinase, are sensitive to the oxidative status of the cell and regulate their activity based on cellular need [119]. Studies looking into the production of sphingolipids illustrated an overproduction of both sphingomyelin and ceramides with HIV-infection, suggesting a lipid imbalance caused by the virus [115, 116, 119]. Additionally, studies showed remarkable deficiencies in antioxidant micronutrients including zinc, selenium, Vitamin C, Vitamin D, Vitamin E and beta-carotene (Vitamin A) [109, 110, 118, 120-126]. Conflicting reports exist on perturbation of total antioxidant status prior to ART, with severalclinical studies reporting decreased total antioxidant capacity [108, 113, 118], while Repetto et al. described an increase in the overall antioxidant capacity as individuals progressed to AIDS [114]. The discrepancies between these findings are likely based on the assays utilized to determine "total antioxidant capacity", as different enzymatic approaches target different portions of the antioxidant system.

Activity levels of superoxide dismutase (SOD), which catalyzes the detoxification of the oxidant superoxide into hydrogen peroxide and water, were assessed by a variety of laboratories. Elevated SOD activity was observed in all evaluated HIV-infected individuals, with further increases occuringwith disease progression to AIDS. In addition, increases in SOD mRNA levels were reported in individuals with HAD, as compared to those who were neurocognitively normal $[114,127,128]$. These changes in SOD were observed in microglial cells, as well as in HIV-infected macrophages, suggesting a virus-triggered induction [128]. An essential antioxidant found in the brain which buffers many reactive oxygen species is glutathione. In HIV-infected patients, overall glutathione levels were found to be reduced, and the remaining glutathione was greatly skewed to the oxidized versus reduced form. $[114,127,129,130]$. The enzyme glutathione peroxidase, which promotes the conversion of hydrogen peroxide to water through the use of glutathione, was also decreased, illustrating a severe imbalance in this system whose goal is to maintain cellular redox homeostasis [121]. Another deleterioius consequence of rampant pro-oxidants within cells is oxidative modification of DNA bases. Increased levels of 5-hydroxyuracil, 5-hydroxycytosine, 8-hydroxyadenine and 8-hydroxyguanine were found when comparing DNA isolated from lymphocytes of HIV-infected individuals versus uninfected controls [131]. One other common product of an imbalanced oxidative state which is beginning to gain more interest and research focus is peroxynitrite. This compound, which is formed when superoxide reacts with nitric oxide, is detectable through its nitrotyrosine moiety, and is found at higher levels and with more frequency in the brains of patients with HAD, compared with those who are neurocognitively normal [128]. In addition to the generation of superoxide as a direct result of HIV infection, the virus also increases mRNA expression of inducible nitric oxide synthase (iNOS), which enables a precipitous accumulation of this deleterious oxidation product [128].Further research in the Nath laboratory has illustrated that thirteen proteins with nitrotyrosine modifications are present in the CSF of individuals with HIV-infection. Individuals with dementia had the highest levels of these nitrites and nitrates. Importantly, three of these proteins were significantly elevated in individuals who showed declines in neurocognitive assessment over a period of 6 months [101]. 
While it appears that there is not an all-or-nothing increase or decrease in antioxidant capacity, the evidence is clear that the components of the antioxidant defense system prior to ART were greatly affected by HIV-infection, and that the capabilities of endogenous antioxidant response were not able to alleviate damaging oxidative alterations to proteins and DNA.

Persistence of oxidative stress in the era of ART: In the ART era, oxidative stress is still pervasive in individuals living with well controlled HIV-infection [102]. In 2007, a group at the University of Pennsylvania sought to ascertain whether ART had an effect on inflammation and oxidative stress in the brains of HIV-infected individuals through utilization of chemical-shift magnetic resonance spectroscopy. Through careful analysis of lipid, lactate, and creatine levels, they determined that the inflammation and oxidative stress initiated by the HIV infection was not ameliorated in ART-treated individuals, compared to seronegative controls [132]. While these effects were observed in all HAND patients, the levels of oxidative stress markers were higher in those with more severe cognitive deficits [132].

Lipid peroxidation is still rampant despite effective viral control. While a couple of studies report decreased levels in markers of lipid peroxidation in ART-medicated patients, as compared with those not receiving ART, multiple studies have shown persistent statistically significant increases in hydroperoxides, isoprostanes, and malondialdehyde in ART-treated HIV-infected individuals, compared to seronegative controls [103, 113, 133-139]. Interestingly, two independent groups have determined in patient blood samples that the levels of peroxide species and oxidative stress are higher in patients on protease inhibitor (PI) based regimens, as compared with those in individuals on non-nucleoside reverse transcriptase inhibitor (NNRTI) based regimens, implicating a role for the protease inhibitor class in induction or exacerbation of oxidative stress $[138,140]$.

Micronutrient deficiencies are still problematic with ART, and while most patients have adequate plasma concentrations of vitamins C, D, and E, reported levels are still considered sub-optimal and lower than seronegative patients [123, 141]. While subsequent reports have indicated that zinc and selenium deficits are no longer observed in individuals on ART, further definitive confirmation of these findings is necessary [142, 143]. Additionally, in studies which evaluated the serum of adults and the saliva of children, the total antioxidant status was found to be decreased in ART treated HIV-patients when compared to HIV-negative controls, mirroring findings in studies conducted in the pre-ART era [104, 144].

While several studies have indicated that introduction of ART has been accompanied by an improvement in overall glutathione status, this effect is not totally rectified and imbalances still occur [129]. In particular, numerous groups have shown that circulating glutathione levels are still markedly reduced in HIV-infected individuals, when compared with age-matched controls, with the ratio of oxidized to reduced glutathione remaining out of balance [112, 133-135, 145]. Unfortunately, studies investigating nitrosative stress and nitrosylated proteins in HIV-infected individuals on ART are still lacking; however, the Nath, Hammond, and Sutliff laboratories have been investigating nitrosative stress in HIV, and it is likely that such reports are forthcoming. 
It has been reported that HIV-positive individuals do not have altered levels of 8-hydroxy-2'-deoxyguanosine [8-oxoG) in their urine regardless of ART or lipodystrophy status [146]. While these findings appear to be promising, in a very recent study, autopsy tissue from frontal cortex was stained for both nuclear and mitochondrial 8-oxoG. The levels of this oxidized DNA product were significantly increased in cases of HAND, suggesting that ART, or ART in combination with ongoing infection may promote DNA oxidative modification, cellular dysfunction damage and death [147]. Additionally, the presence of clastogenic factors, which cause chromosomal breaks and DNA damage and which may be released from cells under conditions of oxidative stress, was observed in the plasma of all HIV-patients tested by Edeas et al. [148]. This was true ofpatients that were both asymptomatic and symptomatic for AIDS-defining pathologies, and was independent of ART status [148]. The effects of these clastogenic factors appear to persist in multiple cell populations implicated in HAND pathogenesis. For example, in leukocytes obtained from HIV-infected individuals, the percentage of cells exhibiting DNA fragmentation was increased in individuals on ART, as compared with those who were ART- naïve [135]. However, the results of this study have not addressed the possible contribution of latent or low level of infection to the findings. Due to pervasive oxidative damage and antioxidant imbalance despite effective long-term viral control in patients, it is now imperative to recognize the direct effect that viral enclaves and antiretroviral drugs themselves may have on perpetuating these effects. Further studies are needed to investigate the independent effects of ART and the virus on oxidative damage in the CNS, as well as in the periphery in order to better determine therapeutic interventions to resolve these dysfunctions.

\subsection{Oxidative stress induction by HIV}

Exhaustive research has been conducted in order to determine the effects of the HIV on infected cells and the cytotoxic factors released from these cells. As addressed earlier, it is now clear that HIV-infected macrophages secrete a variety of neurotoxic substances including glutamate, nitric oxide, and superoxide [96]. Within actively infected human myeloid-monocytic cell lines or monocyte-derived macrophages, HIV induces an increase in superoxide anions, with a concomitant increase in superoxide to combat these factors [128, 149]. Mollace and colleagues have demonstrated that the supernatants from HIV-infected human primary macrophages induced oxidative stress in astrocytes, as indicated by increases in malondialdeyde levels [150]. They further showed that these supernatants, which contained excess superoxide, induced astrocytic apoptosis, confirming HIV-mediated toxicity of this secreted product [150]. In a similar fashion, in HIV-infected monocytes, an induction of nitric oxide synthase and subsequent increase nitric oxide was observed [151]. It is also interesting to note that elevated oxidative stress in the form of intracellular singlet oxygen is capable of reactivating latent HIV through long terminal repeat (LTR) transactivation in infected monocytes or lymphocytes, suggesting that the virus may rely on oxidative stress signaling cascades for continuation of long-term infection or viral rebound [152].

The amino acid and neurotransmitter glutamate is normally secreted from neurons into the synaptic cleft, and is quickly removed and recycled through the actions of astrocytes. This 
molecule normally activates the N-methyl D-aspartate (NMDA) receptor on neurons, and allows for $\mathrm{Ca}^{2+}$ entry into the cell. However, it has been clearly demonstrated that excessive extracellular levels of glutamate resulting from overstimulation of neurons, impaired reuptake by astrocytes, or release from other cell populations within the brain can lead to hyperactivation of NMDA channels, subsequent increases in $\mathrm{Ca}^{2+}$ levels in the neuronal cytoplasm, resulting in excitotoxic neuronal death [153]. In 2001, Jiang et al. demonstrated through a series of elegant experiments that the molecule responsible for the neurotoxicity observed on neuronal cultures was a molecule of less than 3,000 kilodaltons, was not sensitive to trypsin digestion, and that its neurotoxic effect was blocked by a selective NMDA receptor antagonist, MK-801. It was through this study, as well as a subsequent study by O'Donnell et al. that the increased levels of extracellular glutamate secreted by HIV-infected macrophages may be a major factor in HIV-infected macrophage mediated indirect neuronal death [154]. The increases in extracellular glutamate appears to be an effect of dysregulation of the glutamate synthesis pathway, as inhibition of the mitochondrial glutaminase enzyme blocks the production and the secretion of glutamate from HIV-infected macrophages [155-157]. As was distinctly noted in human patient samples, a marked deficiency of glutathione and an imbalance between the oxidized and the reduced glutathione was observed. Within cells, glutaminase is the enzyme which converts glutamine to glutamate. It is tempting to consider that the oxidative stress resulting from the lack of the antioxidant properties of glutamine may be very tightly coupled to a depletion of glutamine from cells by hyperactivation of glutaminase enzymes, precipitating an overproduction of glutamate and triggering an excitotoxic neuronal death pathway.

Similar to effects of whole virus in vivo, when gp120 and Tat were injected into the brains of rats, both of these viral proteins induced lipid peroxidation and glutathione depletion [158]. Additionally, both of these proteins significantly reduced intracellular glutathione, and increased malondialdehyde in immortalized brain endothelial cells, showing that the oxidative status of these cells would also be directly affected by the presence of virus. This is of particular importance as the altered oxidative status of these endothelial cells comprising the $\mathrm{BBB}$ will have potential impact on not only the integrity of the BBB, but also on the monocyte/macrophage transmigration to the CNS, an important factor in the persistence of HAND [159]. Further, when applied to neurons in culture, gp120 and Tat induce disruptions in the lipid metabolism, leading to increased levels of sphingomyelin, ceramide, and hydroxynoneal,paralleling disruptions in these pathways observed in the neurons of HAND patients [116].

Studies that investigated gp120 separately have revealed that it is capable of inducing ROS formation, and activating the antioxidant response in astrocytes [91, 160]. Studies looking into the production of oxidant species by gp120 have shown that superoxide ions as well as nitric oxide are involved in neuronal toxicity [100, 161]. Mechanistically, gp120-induced nitric oxide formation is dependent on a mannose-specific endocytic lectin in macrophages, while gp120-induced expression and upregulation of iNOS selectively occurs in astrocytes in human fetal neuroglial cultures [100, 162]. Multiple studies have shown that in neurons undergoing gp120-induced toxicity, a significant increase in intracellular $\mathrm{Ca}^{2+}$, likely re- 
leased from intracellular stores, preceeded death, suggesting at a mechanism of activation of calpains or other pro-death cellular machinery $[63,160]$.

Studies investigating Tat-induced neuronal death have revealed that this viral protein triggered the accumulation of ROS when exogenously applied to a variety of cell types, including lymphocytes, microglia, brain microvascular endothelial cells (BMECs) and neurons, as well as in HeLa cells expressing Tat [163-166]. When directly injected into striatum of rats, Tat produced dramatic increases in protein oxidative modifications and protein carbonyls [167]. Protein carbonyls were also markedly increased in HeLa cells expressing Tat, supporting in vivo data [166]. In addition, decreased levels of glutathione were observed in cardiac myocytes and BMECs exposed to recombinant Tat protein, Tatexpressing transgenic mice, and in Tat-expressing HeLa cells [164, 168-170]. Two studies pinpointed the involvement of manganese-dependent superoxide dismutase (Mn-SOD) as a key player in Tat- induced cellular changes. By expressing Tat in HeLa cells, the laboratories of Lehman and McCord convincingly showed that Tat suppressed the RNA, protein, and activity levels of Mn-SOD, while inducing no changes in the $\mathrm{Cu}, \mathrm{Zn}$ SOD enzyme levels [166, 170]. In HIV-infected individuals, plasma levels of SOD were increased in plasma, and these changes were in parallel with disease progression to AIDS. If the results from these HeLa cell studies can be expanded to other cell populations, it is tempting to speculate that perhaps this overall increase in SOD activity is a compensatory mechanism resulting from the Tat-induced alterations in Mn-SOD activity and the subsequent increases in superoxide ions that cannot be eliminated. The overexpression of Tat in HeLa cells also led to decreases in overall glutathione levels, with a lower ratio of reduced to oxidized glutathione in the remaining supply, mimicking the effect seen in HIVinfected individuals in vivo and in HIV-infected macrophages in vitro [166, 170].

Finally, studies focusing on microglia have shown that the expression of HIV viral protein $\mathrm{R}$ (Vpr) can induce oxidative stress pathways, and can activate HIV latent gene expression [171]. When exogenously applied to human fetal astrocytes, the oxidative stress caused by Vpr causes decreases in intracellular ATP and glutathione, and skews remaining glutathione in favor of the oxidized versus reduced form [172].

In summary, exhaustive in vivo and in vitro studies indicate that HIV viral proteins themselves can induce, precipitate and augment oxidative stress in multiple cell types, of both peripheral and CNS tissue. These findings further emphasize the importance of complete inhibition of viral replication in alleviating oxidative stress via antiretroviral therapy. However, emerging evidence suggests that antiretroviral drugs themselves might inadvertently lead to oxidative stress.

\subsection{Oxidative stress and ART}

Due to the requirement for lifelong adherence to antiretroviral regimens to prevent viremia and immune system compromise, it is necessary to investigate the effects of these compounds in a cellular context. Many of these drugs are associated with negative side effects, and have been linked to the metabolic syndrome, atherosclerosis, lipodystrophy, proteasome inhibition and the unfolded protein response [173-175]. Additionally, it has become 
apparent that these compounds themselves produce oxidative stress, even in the absence of virus, and may in fact be contributing to the persistence of oxidative stress in patients with well controlled viral load [97, 102].

HIV is highly susceptible to mutations, mostly due to the error-prone reverse transcription step during replication, and underlies the emergence of drug resistant mutations over time in patients treated with single antiretroviral drugs in the early 1990s. Additionally, the development of more sensitive methods for HIV RNA detection revealed the presence of viral reservoirs in multiple tissues, including the CNS. These findings led to the revision of antiretroviral therapy, which, until that time included mostly single antiretroviral drug regimens. A multiple drug treatment approach, termed ART, was implemented to aim at different steps in the HIV replication. Currently recommended ART regimens include a cocktail of nucleoside/nucleotide reverse-transcriptaseinhibitors (NRTIs/NtRTIs), non-nucleoside reverse-transcriptase inhibitors (nNRTIs), protease inhibitors (PIs), and to a lesser extent, entry inhibitors and integrase inhibitors(Panel on Antiretroviral Guidelines for Adults and Adolescents. Guidelines for the use of antiretroviral agents in HIV-1-infected adults and adolescents.Department of Health and Human Services.Available at http://aidsinfo.nih.gov/ contentfiles/lvguidelines/AdultandAdolescentGL.pdf). This approach has led to improved immune function, long-term viral suppression; and underlies the reductions in HIV-associated morbidity and mortality in the era of ART. The recently updated guidelines recommend ART initiation to all HIV- infected, ART-naive individuals irrespective of $\mathrm{CD} 4^{+}$counts and the impact of early initiation of ART on HIV-associated neurological complications remain to be seen. While a concensus has been reached regarding the time to initiate ART based on CD4 cell counts, AIDS-defining illnesses, and certain co-morbidity factors; the panel did not clearly outline strategies to best eradicate the viral reservoirs in the CNS, and to decrease the risk of developing HAND among infected patients.

In the meantime, one major approach to better control HAND has been to implement therapies that include drugs which achieve therapeutic concentrations in the CNS. While HIV can circumvent the BBB barrier, complex drug transport and efflux mechanisms at this junction hampers effective antiretroviral concentrations in the brain parenchyma. Recent efforts to address this hurdle have led to the establishment of CNS penetrance effectiveness (CPE) score, an algorithm based on the chemical structure, pharmacodynamic and pharmacokinetic data of antiretroviral drugs [176-178]. In summary, an antiretroviral drug with high CPE score is small in size (molecular mass below 400-500 kDa), has high lipid solubility and low protein binding, and it is not a substrate for drug transport or efflux proteins. Unfortunately, results of several clinical studies which incorporated CPE into the design and the analysis of outcomes are not conclusive [176, 178-183]. While a positive correlation between CPE scores and neurological outcomes are observed in several studies, one study revealed that ART regimens with higher CPE scores might be associated with worse neurocognitive performance [184].

These studies investigating the effect of CPE scores on neurological outcomes have inherent caveats. First, due to the limited methodologies, the clinical studies cannot assess the drug concentrations in the brain parenchyma, and instead depend on the CSF levels, which are 
usually based on measurements after a single-dose administration of the drug. Several factors, such as poor drug adherence and the impact of co-prescribed drugs on the pharmacokinetics of antiretroviral drugs can impact the CNS concentrations and can confound the measured outcomes.Additionally, the escape of drug-resistant viral species into the CNS and their establishment in viral reservoirs early during infection can lead to the rise of drugresistant HIV species in the CNS, and can hinder the efforts to assess the impact of CPE scores on neurological outcomes. Further, co-morbidity factors impacting the integrity of the BBB should also be considered in assessing drug availability in the CNS. Among these factors are cancer, infections, and drug and alcohol abuse, all of which are shown to alter BBB integrity independent of HIV infection, and should be considered when CPE scores are established and evaluated [185-187]. One final factor to consider in evaluating the long-term effectiveness of ART is the potential direct toxicities of antiretroviral drugs in the CNS, especially given the interest in implementation of ART regimens with better CNS penetrance and possibly developing nanoART as part of treatment plans. Antiretroviral drugs have known side-effects in the periphery, including dyslipidemia, and lipohypertrophy. Further, antiretroviral drug-associated toxicity is well documented in the peripheral nervous system, and potential CNS toxicities secondary to ART exist. Oxidative damage elicited by antiretroviral drugs is of particular interest, given ample evidence of ongoing oxidative stress in the HAND brain, as described above.

In several cavalier studies, researchers eloquently demonstrated in several cell populations (human adipocytes, monocytes, myeloid cell lines, and human aortic endothelial cells) that a variety of drugs from the PI and NRTI families, alone or in combinations, induced the production of ROS, hydrogen peroxide, and factors promoting monocyte recruitment. The compounds reported to induce these changes included PIs: indinavir, nelfinavir, lopinavir, ritonavir, saquinavir, atazanavir and NRTIs: stavudine (d4T), zidovudine (AZT), and didanosine [97-99, 188-191]. The compounds amprenavir (PI) and abacavir (NRTI) were consistently reported as lacking these effects, making these drugs good candidates for inclusion in regimens to be prescribed to patients with HAND [98].

As the first available antiretroviral drug, AZT has been extensively studied. While AZT may not be a mainstay drug of choice for customized optimal regimens, as the primary ART compound available in resource-limited developing countries, it is still of importance to understand its cellular effects. AZT was approved for treatment in 1987, and as early as 1992 the Papoian laboratory reported deficits in mitochondrial enzymes and uncoupling of the electron transport chain (ETC) [192]. The disruption of the ETC is a primary cause of mitochondrial based intracellular ROS accumulation and mitochondrial DNA oxidation, an effect since expounded upon in multiple laboratories after acute AZT exposure in isolated heart mitochondria and primary human cardiomyocytes, and after chronic gestational AZT exposure in mouse liver and kidney and in the lung and brain of fetal patas monkeys [193-196]. This compound has also been shown to increase mitochondrial lipid peroxidation, deplete intracellular glutathione, and lead to oxidation of remaining glutathione, ultimately inducing a caspase-3- and caspase-7- dependent apoptotic death [193, 195, 197]. When another NRTI, d4T was investigated, it also was shown to produce ROS, mitochondrial oxida- 
tive stress, oxidized mitochondrial DNA, and altered activity of mitochondrial oxidative phosphorylation enzymes [198, 199]. Similarly, NRTI zalcitabine (ddC) also induces oxidative stress, as evidenced by the accumulation of protein carbonyls and nitrotyrosine modifications. Interestingly, this study also reported that the better-tolerated cytidine analog lamivudine (3TC) did not produce these effects, suggesting that 3TC may be considered as an alternative to reduce oxidative stress, and that future compounds generated from this structural base may behave similarly [200]. Interestingly, in contrast to studies in human lymphoid cells, Brandmann and collegues have recently reported that in astrocytes AZT, lamivudine, efavirenz, and nevirapine do not appear to reduce intracellular levels of glutathione [190]. Whether or not these compounds behave similarly in neurons and other cell populations in the CNS remains to be elucidated.

In the non-nucleoside reverse transcriptase inhibitor (nNRTI) drug class, efavirenz applied to a human hepatoblastoma cell line resulted in superoxide generation, depletion of intracellular glutathione, and decrease in mitochondrial function and membrane potential that was independent of mitochondrial DNA replication [201]. In addition, efavirenz has also been linked to neuropsychological side effects in HIV-infected patients, and it is probable that the specific oxidative stress effects on mitochondria and glutathione may play a role in the neurotoxicity of this compound, as neurons are particularly sensitive to perturbations in the antioxidant system [201, 202].

Within the protease inhibitor class, both ritonavir and amprenavir have been associated with increased superoxide anion production, while ritonavir has been shown to cause increases in nitrotyrosine levels in porcine coronary arteries [203]. On the other hand, both indinavir and nelfinavir have been shown to induce a time and concentration dependent depletion of intracellular glutathione in astrocytes as well as in pancreatic beta cells [99, 190]. Nelfinavir is of particular interest, as it suppresses cytosolic, rather than mitochondrial superoxide dismutase levels, and induces a necrotic rather than apoptotic cell death cascade in an adipocyte cell line $[99,204]$. Future studies of this compound will undoubtedly prove interesting and may have important implications in patients with regard to their neurocognitive outcomes associated with this compund. Finally, it is interesting to note that multiple studies investigating the oxidative effects of the thymidine analogs in the NRTI class have reported increased ROS, hydrogen peroxide, and nitric oxide intermediates but no superoxide anions [188, 205].

Currently, there is no information on possible oxidative effects of the entry inhibitor, integrase inhibitor, and mutation inhibitor drug classes. Similarly, the lack of published studies for the neuroglial cell populations in the brains of HAND patients is surprising. Several posters at national and international meetings over recent years have addressed this important issue, and hopefully these reports will be forthcoming [206, 207]. In order to design custom drug regimens which will not precipitate, or can ameloirate oxidative stress, cellular dysfunction and death, it is critical to have an understanding of the cellular effects of each currently approved antiretroviral compound, and to design future compounds with minimal oxidative effects. Further, it is possible that the continued dysfunction in superoxide production and superoxide dismutase levels in patients may be due to the effects of more 
than one drug in a multi-drug regimen. Thus, designing future combinations which do not precipiateoxidative stressis of utmost importance in efforts to resolve the persistence of HAND observed in the ART era.

\subsection{Potential therapeutic avenues for oxidative stress in ART era}

Since the manifestations of oxidative stress induced by HIV and ART have emerged, it has also become evident to scientists that boosting the endogenous antioxidant response may be a valid and encouraging adjunctive therapeutic option. Within the cell, the antioxidant response is mediated through the activation of transcription factor NF-E2 (nuclear factor (erythroid-derived 2)-related factor-2 (Nrf2)and its myriad of effector phase II and III detoxifying enzymes. Relevant to the previously discussed aberrations in oxidant detoxification, this pathway upregulates superoxide dismutase, peroxiredoxins, thioredoxins, and multiple glutathione biosynthesis enzymes [208, 209].

In vitro, multiple compounds which act upon the Nrf2 pathway have proven effective in ameliorating the oxidative effects of viral infection, viral proteins or antiretroviral drugs. Among these compounds are resveratrol, dimethyl fumarate, $\mathrm{N}$-acetylcysteine, and curcur$\min [189,191,193,203,210]$. Antioxidants which have not yet been shown to act through the Nrf2 pathway, but which have similar effects in vitro include dihydroxybenzyl alcohol, water soluble vitamin E (trolox), glutathione mimetic tricyclodecan-9-yl-xanthogenat, and acetyl-1-carnitine [188, 200, 201, 211]. An alternative approach to specifically inhibit the actions of NADPH oxidase through the compound diphenyleneiodonium, was able to specifically prevent the effects of PIs, but not NRTIs in human adipocytes [98]. This interesting finding suggests that the different antiretroviral classes may lead to ROS production through different mechanisms, and that specific therapeutics targeting individual oxidant-producing enzymes or pathways may need to be considered for specific ART regimens.

An alternative approach to activating Nrf2 pathway is supplementation with the antioxidant vitamin C (ascorbate), which is capable of directly scavenging reactive oxygen and nitrogen species. This method has been shown to be effective in counteracting the deleterious effects of gp120, as well as nelfinavir in vitro, and has been shown to have beneficial outcomes in patients, when supplemented to ART regimens [100, 195, 204]. Along these same lines, supplementation with a variety of other antioxidants and micronutrients including minocycline, glutathione replenishing peptide alpha-lipoic acid, selenium, vitamin A, Vitamin E, and a multivitamin regimen including vitamins $A, C$, E selenium and coenzyme Q10 have demonstrated partial protection from the deleterious oxidative effects of HIV/SIV and ART in vivo, with particular emphasis on restoration of the total blood glutathione levels [127, 195, 212-214]. Finally, the NMDA-receptor blocker memantine, and monoamide oxidase type B inhibitor selegiline, approved for treatment in Alzheimer and Parkinson Diseases, respectively, have also been proposed as potential therapeutics for HAND [1, 214]. Memantine might exert therapeutic effects through reduction of residual virus-mediated glutamate excitotoxicity, and selegiline has been reported to be capable of reducing oxygenbased free radicals $[215,216]$. The use of these compounds and their efficacy in reducing oxidative damage in HAND are still in early stages. Initial studies were confounded by the fact 
that much damage was already present in late stage HAD patients and a protective effect at this stage was not evident [217]. Further work with these compounds will require identifying patients with ANI or MND to enroll in longitudinal studies to determine whether these compounds will have long-term benefit.

Going forward, it is imperative that the oxidative stress imposed by HIV and ART are targeted by adjunctive therapies. As research progresses with the quest for eliminating viral reservoirs and designing more effective, less toxic antiretroviral compounds, it is important to keep in mind that oxidative stress is and will continue to be a persistent burden, especially in a patient population with a significantly enhanced life expectancy.

\section{The impact of co-morbidities on HAND}

HIV, once an acute and catastrophic infection, has now become a chronic and manageable disease, with advances made in diagnosis and treatment. These changes are reflected in the increases in life expectancy from 5 years to up to the projected 50 years from the time of diagnosis. However, with the increased lifespan, co-morbidities, such as chronic co-infections, substance abuse, and aging have become major contributors to HAND persistence, and need to be addressed for successful evaluation and treatment of HAND.

The compromised immune system in an HIV-infected individual increases the risk of opportunistic infections in the CNS, much like that observed in the peripheral tissue. Most commonly observed infections, CNS toxoplasmosis, cryptococcosis, CNS tuberculosis, and cytomegalovirus encephalitis can be treated successfully by a combination of antimicrobials, antiviral and antiretroviral drugs. However, there are several other viral agents that can either directly target or indirectly compromise CNS, and cannot be readily managed by antiretroviral drugs or chemotherapeutics. One important virus with serious complications in HAND patients is JC virus, the causative agent of progressive multifocal leukoencephelopathy (PML). While approximately $60-80 \%$ of adults globally are seropositive for JC virus, it leads to the development of PML mostly in individuals who are immuno-compromised, either due to an underlying cancer or immunosuppressive treatment, or who are HIV-positive. The current incidence of PML in HIV patients is 3\%. Studies have shown that JC virus can traffic across the BBB within the B cells, can enter the CNS as a free virus, or can infect brain vascular endothelial cells. Once in the CNS, JC virus causes the lytic infection of oligodendrocytes, and results in multifocal demyelination in multiple regions of the white matter. Thus, PML may exacerbate white matter loss that may already be occurring in HAND patients. Further, the most efficient, however limited, treatment for PML, which is immune restoration with aggressive antiretroviral therapy, can potentiate immune reconstitution inflammatory syndrome (IRIS). IRIS, a T-cell mediated encephalitis, can precipitate further injury and worsening of neurological symptoms. While fatality due to PML in HIV-infected individuals can be as high as $50 \%$, the number of cases with non-lethal PML is increasing and PML may be contributing to the persistence of HIV-associated neurological complications. 
Hepatitis B and C (HBV and HCV) are also commonly found in HIV-infected individuals due to the shared risk factors of contracting the virus. While these viruses are not thought to target the primary cells of the CNS, a recent study has reported the presence of HCV antigens in astrocytes and the cells of the macrophage/microglial lineage in the human brain. Additionally, there is limited evidence suggesting that HCV core protein might be detrimental to neurons in vitro and in vivo. Further, several studies have suggested that HCV and HIV can potentiate each other's replication. Currently, there is no conclusive data regarding a possible correlation between HCV presence in the CNS and the neurocognitive deficits in HAND patients. However, the potential implications of $\mathrm{HCV}$ infection in the CNS are at least three-fold. First, HCV co-infection can hinder the efforts to suppress HIV replication in the CNS. Second, weakened immune system function secondary to HCV will negatively impact subsequent alleviation of neurocognitive functions. Finally, compromised functioning of CNS support cells, mainly astrocytes, secondary to concomitant HCV infection will augment the neuroinflammatory environment with a negative impact on neuronal health. These implications may underlie the evidence that suggests that viral suppression and $\mathrm{CD}^{+}$cell recovery is not as successful in the presence of $\mathrm{HCV}$, and might partially explain the sporadic data suggesting that worse neurocognitive impairment is observed in HIV-HCV co-infected patients [184].

Illicit drug use, as well as alcohol abuse, put HIV-positive patients at a greater risk for HAND [6, 218-224]. The prevalence of HIV infection is $11-17 \%$ among illicit drug users, and methamphetamine (METH) is among the most frequently abused drug with well-known toxic effects on the BBB and in the CNS [220]. HIV-infected patients using METH exhibit more neurocognitive deficits, compared to those not using METH. These findings are likely due to the effects of METH on several fronts in the CNS. First, extensive studies have conclusively shown that METH alters the BBB permeability through direct damage to the BMECs, which in turn can augment HIV access to the CNS. Additionally, METH can exert neurotoxic effects in the CNS through oxidative stress and mitochondrial dysfunction [184], and precipitate further synaptic and neuronal damage. METH may also interfere with the expected benefits of ART in several ways. Most importantly, studies have shown that altered patient behavior due to METH use can interfere with drug adherence. Secondly, altered BBB function in a patient using METH can potentially alter antiretroviral access to the CNS, hindering efforts to establish an efficient regimen with limited side effects.

\section{Aging and HAND}

The widespread use of ART has drastically decreased the incidence of AIDS-related complications and improved the long-term prognosis of HIV-positive individuals. Currently, 30\% of the HIV-positive population in the United States is over the age of 50,and by 2015 it is estimated that more than $50 \%$ will be over the age of $50[225,226]$. Despite this remarkable development, the life expectancy for ART-treated HIV-positive individuals remains 10-30 years less than that of uninfected individuals [227]. Given the rapid global expansion of this 
population, it has become increasingly important to understand the risk factors that lie at the intersection of HIV, ART, and aging.

Older HIV-positive patients, including those treated with ART, are at increased risk for systemic diseases including atherosclerosis, liver and kidney failure, cancer, and osteoporosis $[227,228]$. The aging brain may also be more vulnerable to the effects of HIV as older adults display an increased susceptibility to HAND, and emerging evidence suggests an increased prevalence of neurodegenerative diseases, including Alzheimer and Parkinson, in this patient population [229, 230]. It remains unclear if the increased prevalence of HAND is a result of HIV and related comorbidities, including hypertension, insulin resistance, and lipodystrophy, or other confounding factors such as immunosenescence and ART toxicities, all of which are likely to impact CNS disease progression in older HIVpositive individuals [231, 232].

Antiretroviral therapy effectively limits HIV disease progression, maintains patients in a state of partial immune competence, and arrests subjects in a pre-symptomatic state [233]. However, despite the ability of ART to reduce plasma HIV RNA to undetectable levels, HIV-positive individuals remain at higher risk for opportunistic illnesses and premature death [234, 235]. Thus, ART may reduce, but does not appear to eliminate, premature and/or accelerated aging in HIV-infected individuals. This may be attributed to many factors including drug toxicity and slower immune recovery following ART initiation in older patients, compared to younger adults [236]. Furthermore, advanced age has been linked to decreased production of T cells, B cells, and cytokines as well as to chronic immune activation, the latter of which may be linked to the breakdown of gut-associated lymphoid tissue (GALT) and to the elevated levels of systemic lipopolysaccharide (LPS) [237, 238].

Older patients also display a dampened recovery of CD4 cells following treatment with $\mathrm{ART}$, which may increase their risk for systemic diseases ranging from heart disease to cancer [238]. Thus, it is not surprising that advanced age at seroconversion and/or onset of ART treatment is considered a major risk factor for severe HIV disease [239, 240]. Goetz, et al. performed a retrospective study on HIV-positive patients receiving ART treatment at the Veteran's Administration Greater Los Angeles Medical center between 1996 and 1999, and found that for every 10 years of additional age at the onset of ART treatment, the rate of CD4 cell replenishment decreased by 35 cells per microliter of blood [241]. Yet, despite the obvious benefits of beginning ART treatment in asymptomatic HIV-positive individuals, there remain significant concerns for initiating drug therapy sooner than necessary and how this may negatively impact drug toxicity, long-term patient outcome, and the evolution of drug resistant strains of HIV [240, 242]. Based on the updated recommendations for treatment initiation, as mentioned previously, all HIV-infected individuals will be put on ART regimen upon diagnosis, and the impact of this approach on older patients will be revealing.

Lower CD4 count, in addition to advanced age, also places older patients at a nearly fourfold higher risk for liver-related mortality compared to younger patients [243]. This risk is exacerbated by other factors commonly afflicting ART-treated, HIV-positive individuals including diabetes, alcohol abuse, as well as antiretroviral and cholesterol drug toxicity [243]. Among all non-AIDS-related complications, liver disease is the primary cause of death in 
HIV-positive patients [243]. In addition, older HIV-positive individuals are at increased risk for frailty, bone loss and non-AIDS related cancers [244, 245]. It remains unclear if HIV itself places older individuals at higher risk for heart disease compared to older, HIV-negative individuals, though specific classes of antiretrovirals, especially protease inhibitors, have been linked to atherosclerosis [237, 246, 247].

The CNS is particularly susceptible to the synergistic neurodegenerative effects of HIV and aging. Several studies have demonstrated that, compared to younger (age 20 to 39 years) cohorts, older HIV-positive individuals (age > 50 years) display decreased neurocognitive functioning in several areas including memory, psychomotor speed, and executive functions $[225,248,249]$. The persistence of HAND in individuals with an undetectable viral load and CD4 cell counts greater than $200 / \mu \mathrm{L}$ is not well understood and may be a result of agingassociated processes rendering the cells of the CNS more vulnerable.

Several recent neuroimaging studies have begun to address the structural, physiological, and functional changes in the CNS in the context of HIV and aging. Six MRI investigations that assessed the structural changes in the brains of older HIV-positive individuals between 1998 and 2012 found evidence of premature or accelerated aging characterized by significant brain atrophy in the basal ganglia, cerebellum, and frontal and temporal brain regions, when compared to seronegative controls [231]. However, several diffusion tensor imaging (DTI) studies found only normal, age-dependent changes in mean diffusion and fractional anisotropy, which reflects the directionality of water diffusion in the brain, and is greater along organized white matter tracts but decreased in pathologically damaged, disorganized tracts [231, 250-252].

Other studies have employed proton magnetic resonance spectroscopy (MRS) to assess the changes in brain metabolite levels that are indicative of neuronal damage and death or glial activation. Ernst and Chang demonstrated a five-fold acceleration of aging effects in a relatively young (mean age 36 years) ART-naïve, HIV-positive cohort, as compared to HIV-negative controls, as reflected by increased levels of glial activation markers, myoinositol (MI) and choline compounds $(\mathrm{CHO})$, and a decrease in the neuronal marker, $\mathrm{N}$-acetylaspartate (NAA) [253]. A recent multicenter MRS study of slightly older (ages 30-70], ART-treated HIV-positive individuals demonstrated elevated $\mathrm{MI}$ and $\mathrm{CHO}$ in all brain regions of patients with asymptomatic or mild neurocognitive impairment, but decreased levels of MI in those with dementia, which the authors interpreted as premature microglial senescence $[231,254]$. In addition, this study found an age-dependent decrease in NAA in frontal white matter, but only in patients with HAD [254]. Thus, while ART-naïve HIV-positive patients show evidence of increased, age-dependent glial activation and neuronal damage leading to accelerated aging, ART-treated individuals show only signs of premature aging [231].

As mentioned previously, the clinical and pathological hallmarks of post-ART HAND differ from those in the pre-ART era. While HAD presented as a subcortical dementia afflicting the basal ganglia and white matter, some post-ART studies suggest the focus of neuroinflammation has shifted primarily to the hippocampus, even in effectively treated patients [255-257]. Furthermore, there is emerging evidence that pathologic similarities exist between HAND and some common neurodegenerative disorders such as Alzheimer Disease, which is char- 
acterized by the presence of extracellular beta amyloid (A $\beta)$ plaque deposits, and intracellular neurofibrillary tangles composed of hyperphosphorylated Tau [228, 233, 258, 259]. In vitro work involving the viral protein Tat has demonstrated the ability of this viral protein to inhibit the activity of the $A \beta$-degrading enzyme, Neprilysin, and the ability to bind to the receptor for advanced glycation end products, all of which may promote $A \beta$ accumulation in the CNS. Indeed, some individuals with HAND display CSF levels of A $\beta 42$ comparable to those observed in AD patients [228, 260, 261]. However, a recent report utilizing the amyloid-binding, carbon 11-labeled Pittsburgh compound B (11C-PiB) and PET imaging found that irrespective of neurocognitive impairment, HIV-positive individuals showed no increase in 11C-PiB levels, highlighting a potential key difference between $\mathrm{A} \beta$ metabolism in HAND vs. AD despite some overlapping pathological features [258].

Among the studies underlining the similarities between HAND and AD, Esiri et al. were the first to report a predisposition to plaque formation in the brains of pre-ART HIV-positive individuals [262]. Such pathological changes have been observed in HIV-positive patients despite successful virologic control with ART, suggesting that antiretrovirals either cannot achieve therapeutic concentrations within the brain parenchyma, allowing for ongoing viral replication and neuroinflammation, or may have toxic effects that could facilitate neurodegeneration [263, 264]. To address the latter concern, several reports investigated differences in either phospho-tau or beta amyloid levels in ART-naïve vs. ART-treated individuals. Two groups independently reported elevated $\mathrm{A} \beta$ deposition in the hippocampus of ART-treated individuals compared to pre-ART patients, yet Anthony et al. reported only increased hyperphosphorylated tau, but no $\mathrm{A} \beta$ deposition in the hippocampus and entorhinal cortex of HIV-positive individuals [257, 259, 265]. To date, no group has reported concomitant phospho-tau and $\mathrm{A} \beta$ plaque depositions in the same brain samples from HIV-positive cohorts. Differences in patient age and ART-regimens, as well as the antibodies used to detect A $\beta$ may account for the varied outcomes of these reports.

Importantly, the aforementioned studies highlight the potentially under-appreciated concern of antiretroviral-associated toxicity and its effect on neuropsychological outcomes in long-term ART-treated patients. As described earlier, ART drugs have been linked to wide-ranging, peripheral metabolic and neural disturbances that could themselves influence the progression of HAND and foretell potential mechanisms of toxicity in the CNS [246, 266-276]. While CNS effects of ART are poorly understood, Schweinsburg et al. demonstrated an association between NRTIs and decreased levels of frontal white matter NAA, which they attributed to NRTI-mediated mitochondrial dysfunction and depletion of cellular respiration [268]. Confounding the issue of direct CNS toxicity of antiretroviral medications is the variability in BBB permeability amongst different drug classes as determined by various physicochemical properties such as plasma protein binding, lipophilicity, and molecular size.

Although it is a widely held that ART regimens with higher CNS penetrance generally confer greater neuropsychological outcomes in HIV-positive individuals, numerous clinical studies have suggested these regimens may negatively impact cognition. In a prospective study, Marra et al. found a significant association between highly CNS- 
penetrant ART regimens and worse neurocognitive and motor performance, despite decreased CSF HIV RNA in a small HIV-positive cohort [181]. In addition, Robertson et al. reported an improvement in neuropsychological outcome in a cohort of patients with interrupted drug treatment [277]. Studies using SCID mice, which display neuropathological hallmarks similar to those associated with HIV, showed reduced viral load and astrogliosis following administration of ART, but no improvement in cognitive dysfunction [278]. Altogether, these studies reinforce an emerging hypothesis that antiretroviral drugs may be contributing to the rising prevalence of HAND in the aging HIV-positive population.

However, many clinical studies have demonstrated beneficial effects on neurocognitive functioning by ART regimens with high CPE scores [279, 280]. A cross-sectional study of 2636 adults from the AIDS Clinical Trials Group Longitudinal Linked Randomized Trials (ALLRT cohort), on effective ART for at least 6 weeks showed better neurocognitive performance in individuals receiving ART medications with higher CPE scores [281]. In some cases, participants required more than 3 antiretrovirals to treat HIV in the CNS. Letendre et al. demonstrated improvements in cognition over a 15-week period in patients beginning ART with higher CPE ART regimens [282]. Another recent investigation utilized MRS imaging to investigate the effect of different CPE ART regimens with different CPE scores on changes in brain NAA metabolite levels. Over 48 weeks, HIV-positive, ART-naïve individuals receiving the regimens with highest CPE scores displayed the highest increases in NAA levels, and showed the greatest improvement in a battery of neuropsychological tests [283]. These studies suggest that ART medications with higher CNS penetrance may have a neuroprotective effect in successfully treated HIV-positive adults. However, given the well-characterized toxicities of ART medications in the periphery, and the potential impact of related co-morbidities on CNS pathology, it may be necessary to consider adjunctive therapies to minimize the synergistic effects of ART and aging in HIV-positive individuals.

\section{Summary}

The advent of ART has profoundly changed the landscape of disease; however, neurocognitive impairments continue to be debilitating to patients with the expected life expectancy closer to that of the uninfected population. A better understanding and appreciation of the confounding factors has become more acute as the recent focus in the race to cure AIDS has shifted towards the eradication of latent viral reservoirs, including those in the CNS. It is imperative to anticipate and control the immune responses due to viral reactivation, the potential neurotoxicities of viral proteins in the brain parenchyma when latent viral progeny is activated, and the oxidative damage that may be precipitated by viral particles and the activated immune cells. These factors will be even more crucial to control in the aging brain with limited cognitive reserves. 


\section{Author details}

Jennifer M. King, Brigid K. Jensen, Patrick J. Gannon and Cagla Akay*

*Address all correspondence to: akayc@upenn.edu

Department of Pathology, School of Dental Medicine, University of Pennsylvania, Philadelphia, USA

\section{References}

[1] Lindl KA, Marks DR, Kolson DL, Jordan-Sciutto KL. HIV-associated neurocognitive disorder: pathogenesis and therapeutic opportunities. J Neuroimmune Pharmacol. (Review). 2010 Sep;5 (3):294-309.

[2] Antinori A, Arendt G, Becker JT, Brew BJ, Byrd DA, Cherner M, et al. Updated research nosology for HIV-associated neurocognitive disorders. Neurology. 2007 Oct 30;69 (18):1789-99.

[3] Heaton RK, Clifford DB, Franklin DR, Jr., Woods SP, Ake C, Vaida F, et al. HIV-associated neurocognitive disorders persist in the era of potent antiretroviral therapy: CHARTER Study. Neurology. 2010 Dec 7;75 (23):2087-96.

[4] Dore GJ, Correll PK, Li Y, Kaldor JM, Cooper DA, Brew BJ. Changes to AIDS dementia complex in the era of highly active antiretroviral therapy. AIDS (London, England). 1999 Jul 9;13 (10):1249-53.

[5] Dore GJ, Li Y, McDonald A, Ree H, Kaldor JM. Impact of highly active antiretroviral therapy on individual AIDS-defining illness incidence and survival in Australia. Journal of acquired immune deficiency syndromes (1999). 2002 Apr 1;29 (4):388-95.

[6] Power C, Boisse L, Rourke S, Gill MJ. NeuroAIDS: an evolving epidemic. Can J Neurol Sci. 2009 May;36 (3):285-95.

[7] Price RW, Brew B, Sidtis J, Rosenblum M, Scheck AC, Cleary P. The brain in AIDS: central nervous system HIV-1 infection and AIDS dementia complex. Science. 1988;239:586-92.

[8] Gongvatana A, Schweinsburg BC, Taylor MJ, Theilmann RJ, Letendre SL, Alhassoon $\mathrm{OM}$, et al. White matter tract injury and cognitive impairment in human immunodeficiency virus-infected individuals. J Neurovirol. 2009 Apr;15 (2):187-95.

[9] Thompson PM, Dutton RA, Hayashi KM, Toga AW, Lopez OL, Aizenstein HJ, et al. Thinning of the cerebral cortex visualized in HIV/AIDS reflects CD4+ T lymphocyte decline. Proc Natl Acad Sci U S A. 2005 Oct 25;102 (43):15647-52.

[10] Cohen RA, Harezlak J, Schifitto G, Hana G, Clark U, Gongvatana A, et al. Effects of nadir CD4 count and duration of human immunodeficiency virus infection on brain 
volumes in the highly active antiretroviral therapy era. J Neurovirol. 2010 Feb;16 (1): 25-32.

[11] Ellis R. HIV and antiretroviral therapy: impact on the central nervous system. Prog Neurobiol. 2010 Jun;91 (2):185-7.

[12] Everall I, Vaida F, Khanlou N, Lazzaretto D, Achim C, Letendre S, et al. Cliniconeuropathologic correlates of human immunodeficiency virus in the era of antiretroviral therapy. J Neurovirol. 2009 Sep;15 (5-6):360-70.

[13] Everall IP, Heaton RK, Marcotte TD, Ellis RJ, McCutchan JA, Atkinson JH, et al. Cortical synaptic density is reduced in mild to moderate human immunodeficiency virus neurocognitive disorder. HNRC Group. HIV Neurobehavioral Research Center. Brain Pathol. 1999 Apr;9 (2):209-17.

[14] Masliah E, Heaton RK, Marcotte TD, Ellis RJ, Wiley CA, Mallory M, et al. Dendritic injury is a pathological substrate for human immunodeficiency virus-related cognitive disorders. HNRC Group. The HIV Neurobehavioral Research Center. Ann Neurol. 1997 Dec;42 (6):963-72.

[15] Zheng J, Thylin MR, Cotter RL, Lopez AL, Ghorpade A, Persidsky Y, et al. HIV-1 infected and immune competent mononuclear phagocytes induce quantitative alterations in neuronal dendritic arbor: relevance for HIV-1-associated dementia. Neurotox Res. 2001 Oct;3 (5):443-59.

[16] Gelman BB, Schuenke K. Brain aging in acquired immunodeficiency syndrome: increased ubiquitin-protein conjugate is correlated with decreased synaptic protein but not amyloid plaque accumulation. J Neurovirol. 2004 Apr;10 (2):98-108.

[17] Kolson DL, Sabnekar P, Baybis M, Crino PB. Gene expression in TUNEL-positive neurons in human immunodeficiency virus-infected brain. J Neurovirol. 2004;10 Suppl 1:102-7.

[18] Wiley CA, Achim CL, Hammond R, Love S, Masliah E, Radhakrishnan L, et al. Damage and repair of DNA in HIV encephalitis. J Neuropathol Exp Neurol. 2000 Nov;59 (11):955-65.

[19] Gonzalez-Scarano F, Martin-Garcia J. The neuropathogenesis of AIDS. Nat Rev Immunol. 2005 Jan;5 (1):69-81.

[20] Fauci AS. The human immunodeficiency virus: infectivity and mechanisms of pathogenesis. Science. 1988 Feb 5;239 (4840):617-22.

[21] Williams DW, Eugenin EA, Calderon TM, Berman JW. Monocyte maturation, HIV susceptibility, and transmigration across the blood brain barrier are critical in HIV neuropathogenesis. J Leukoc Biol. 2012 Mar;91 (3):401-15.

[22] Roberts TK, Buckner CM, Berman JW. Leukocyte transmigration across the bloodbrain barrier: perspectives on neuroAIDS. Front Biosci. 2010;15:478-536. 
[23] Liu NQ, Lossinsky AS, Popik W, Li X, Gujuluva C, Kriederman B, et al. Human immunodeficiency virus type 1 enters brain microvascular endothelia by macropinocytosis dependent on lipid rafts and the mitogen-activated protein kinase signaling pathway. J Virol. 2002 Jul;76 (13):6689-700.

[24] Gendelman HE, Lipton SA, Tardieu M, Bukrinsky MI, Nottet HS. The neuropathogenesis of HIV-1 infection. (see comment). (Review) (107 refs). 1994 Sep.

[25] Gonzalez-Scarano F, Martin-Garcia J. The neuropathogenesis of AIDS. (Review) (173 refs). 2005 Jan.

[26] Kaul M, Zheng J, Okamoto S, Gendelman HE, Lipton SA. HIV-1 infection and AIDS: consequences for the central nervous system. (Review) (199 refs). 2005 Aug.

[27] Carter CC, Onafuwa-Nuga A, McNamara LA, Riddell Jt, Bixby D, Savona MR, et al. HIV-1 infects multipotent progenitor cells causing cell death and establishing latent cellular reservoirs. Nat Med. 2010 Apr;16 (4):446-51.

[28] Hakre S, Chavez L, Shirakawa K, Verdin E. HIV latency: experimental systems and molecular models. FEMS Microbiol Rev. 2012 May;36 (3):706-16.

[29] Lafeuillade A. Eliminating the HIV reservoir. Curr HIV/AIDS Rep. 2012 Jun;9 (2): 121-31.

[30] Saleh S, Wightman F, Ramanayake S, Alexander M, Kumar N, Khoury G, et al. Expression and reactivation of HIV in a chemokine induced model of HIV latency in primary resting CD4+ T cells. Retrovirology. 2011;8:80.

[31] Vandergeeten C, Fromentin R, Chomont N. The role of cytokines in the establishment, persistence and eradication of the HIV reservoir. Cytokine Growth Factor Rev. 2012 Aug;23 (4-5):143-9.

[32] Wilen CB, Tilton JC, Doms RW. Molecular mechanisms of HIV entry. Adv Exp Med Biol. 2012;726:223-42.

[33] Devadas K, Hardegen NJ, Wahl LM, Hewlett IK, Clouse KA, Yamada KM, et al. Mechanisms for macrophage-mediated HIV-1 induction. J Immunol. 2004 Dec 1;173 (11):6735-44.

[34] Gorry PR, Ong C, Thorpe J, Bannwarth S, Thompson KA, Gatignol A, et al. Astrocyte infection by HIV-1: mechanisms of restricted virus replication, and role in the pathogenesis of HIV-1-associated dementia. Curr HIV Res. 2003 Oct;1 (4):463-73.

[35] Wraith DC, Nicholson LB. The adaptive immune system in diseases of the central nervous system. J Clin Invest. 2012 Apr 2;122 (4):1172-9.

[36] Ransohoff RM, Brown MA. Innate immunity in the central nervous system. J Clin Invest. 2012 Apr 2;122 (4):1164-71.

[37] Fairweather D, Cihakova D. Alternatively activated macrophages in infection and autoimmunity. J Autoimmun. 2009 Nov-Dec;33 (3-4):222-30. 
[38] Fujiwara N, Kobayashi K. Macrophages in inflammation. Curr Drug Targets Inflamm Allergy. 2005 Jun;4 (3):281-6.

[39] Tesseur I, Wyss-Coray T. A role for TGF-beta signaling in neurodegeneration: evidence from genetically engineered models. Curr Alzheimer Res. 2006 Dec;3 (5): 505-13.

[40] Wahl SM, Allen JB, McCartney-Francis N, Morganti-Kossmann MC, Kossmann T, Ellingsworth L, et al. Macrophage- and astrocyte-derived transforming growth factor beta as a mediator of central nervous system dysfunction in acquired immune deficiency syndrome. J Exp Med. 1991 Apr 1;173 (4):981-91.

[41] Wahl SM. The role of transforming growth factor-beta in inflammatory processes. Immunol Res. 1991;10 (3-4):249-54.

[42] Johnson MD, Gold LI. Distribution of transforming growth factor-beta isoforms in human immunodeficiency virus-1 encephalitis. Hum Pathol. 1996 Jul;27 (7):643-9.

[43] Dhar A, Gardner J, Borgmann K, Wu L, Ghorpade A. Novel role of TGF-beta in differential astrocyte-TIMP-1 regulation: implications for HIV-1-dementia and neuroinflammation. J Neurosci Res. 2006 May 15;83 (7):1271-80.

[44] Samah B, Porcheray F, Dereuddre-Bosquet N, Gras G. Nerve growth factor stimulation promotes CXCL-12 attraction of monocytes but decreases human immunodeficiency virus replication in attracted population. J Neurovirol. 2009 Jan;15 (1):71-80.

[45] Meeker RB, Poulton W, Markovic-Plese S, Hall C, Robertson K. Protein changes in CSF of HIV-infected patients: evidence for loss of neuroprotection. J Neurovirol. (Research Support, N.I.H., Extramural). 2011 Jun;17 (3):258-73.

[46] Heath SL, Sabbaj S, Bansal A, Kilby JM, Goepfert PA. CD8 T-cell proliferative capacity is compromised in primary HIV-1 infection. Journal of acquired immune deficiency syndromes (1999). 2011 Mar;56 (3):213-21.

[47] Yadav A, Collman RG. CNS inflammation and macrophage/microglial biology associated with HIV-1 infection. J Neuroimmune Pharmacol. 2009 Dec;4 (4):430-47.

[48] Tozzi V, Balestra P, Bellagamba R, Corpolongo A, Salvatori MF, Visco-Comandini U, et al. Persistence of neuropsychologic deficits despite long-term highly active antiretroviral therapy in patients with HIV-related neurocognitive impairment: prevalence and risk factors. Journal of acquired immune deficiency syndromes (1999). 2007 Jun $1 ; 45(2): 174-82$.

[49] Yilmaz A, Price RW, Spudich S, Fuchs D, Hagberg L, Gisslen M. Persistent intrathecal immune activation in HIV-1-infected individuals on antiretroviral therapy. Journal of acquired immune deficiency syndromes (1999). 2008 Feb 1;47 (2):168-73.

[50] Yilmaz A, Fuchs D, Hagberg L, Nillroth U, Stahle L, Svensson J-O, et al. Cerebrospinal fluid HIV-1 RNA, intrathecal immunoactivation, and drug concentrations after 
treatment with a combination of saquinavir, nelfinavir, and two nucleoside analogues: the M61022 study. BMC Infectious Diseases. 2006;6 (1):63.

[51] Edén A, Fuchs D, Hagberg L, Nilsson S, Spudich S, Svennerholm B, et al. HIV-1 Viral Escape in Cerebrospinal Fluid of Subjects on Suppressive Antiretroviral Treatment. Journal of Infectious Diseases. 2010 December 15, 2010;202 (12):1819-25.

[52] Hagberg L, Cinque P, Gisslen M, Brew B, Spudich S, Bestetti A, et al. Cerebrospinal fluid neopterin: an informative biomarker of central nervous system immune activation in HIV-1 infection. AIDS Research and Therapy. 2010;7 (1):15.

[53] Achim CL, Masliah E, Heyes MP, Sarnacki P, Hilty C, Baldwin M, et al. Macrophage Activation Factors<br / >in the Brains of AIDS Patients. Journal of neuro-AIDS. 1996;1 (2):1-16.

[54] Achim CL, Wiley CA. Inflammation in AIDS and the role of the macrophage in brain pathology. Curr Opin Neurobiol. 1996;9 (3):221-5.

[55] Conant K, Garzino-Demo A, Nath A, McArthur JC, Halliday W, Power C, et al. Induction of monocyte chemoattractant protein-1 in HIV-1 Tat-stimulated astrocytes and elevation in AIDS dementia. Proc Natl Acad Sci U S A. 1998 Mar 17;95 (6): 3117-21.

[56] Gisolf EH, van Praag RM, Jurriaans S, Portegies P, Goudsmit J, Danner SA, et al. Increasing cerebrospinal fluid chemokine concentrations despite undetectable cerebrospinal fluid HIV RNA in HIV-1-infected patients receiving antiretroviral therapy. Journal of acquired immune deficiency syndromes (1999). 2000 Dec 15;25 (5):426-33.

[57] Sippy BD, Hofman FM, Wallach D, Hinton DR. Increased expression of tumor necrosis factor-alpha receptors in the brains of patients with AIDS. J Acquir Immune Defic Syndr Hum Retrovirol. 1995 Dec 15;10 (5):511-21.

[58] Tomkowicz B, Lee C, Ravyn V, Cheung R, Ptasznik A, Collman RG. The Src kinase Lyn is required for CCR5 signaling in response to MIP-1beta and R5 HIV-1 gp120 in human macrophages. Blood. 2006 Aug 15;108 (4):1145-50.

[59] Lee C, Tomkowicz B, Freedman BD, Collman RG. HIV-1 gp120-induced TNF-\{alpha\} production by primary human macrophages is mediated by phosphatidylinositol-3 (PI-3) kinase and mitogen-activated protein (MAP) kinase pathways. J Leukoc Biol. 2005 Oct;78 (4):1016-23.

[60] Chihara T, Hashimoto M, Osman A, Hiyoshi-Yoshidomi Y, Suzu I, Chutiwitoonchai $\mathrm{N}$, et al. HIV-1 proteins preferentially activate anti-inflammatory M2-type macrophages. J Immunol. 2012 Apr 15;188 (8):3620-7.

[61] Turchan-Cholewo J, Dimayuga VM, Gupta S, Gorospe RM, Keller JN, Bruce-Keller AJ. NADPH oxidase drives cytokine and neurotoxin release from microglia and macrophages in response to HIV-Tat. Antioxid Redox Signal. 2009 Feb;11 (2):193-204. 
[62] Pu H, Tian J, Flora G, Lee YW, Nath A, Hennig B, et al. HIV-1 Tat protein upregulates inflammatory mediators and induces monocyte invasion into the brain. Mol Cell Neurosci. 2003 Sep;24 (1):224-37.

[63] Agrawal L, Louboutin JP, Marusich E, Reyes BA, Van Bockstaele EJ, Strayer DS. Dopaminergic neurotoxicity of HIV-1 gp120: reactive oxygen species as signaling intermediates. Brain Res. 2010 Jan 8;1306:116-30.

[64] Louboutin JP, Agrawal L, Reyes BA, Van Bockstaele EJ, Strayer DS. Protecting neurons from HIV-1 gp120-induced oxidant stress using both localized intracerebral and generalized intraventricular administration of antioxidant enzymes delivered by SV40-derived vectors. Gene Ther. 2007 Dec;14 (23):1650-61.

[65] Agrawal L, Louboutin JP, Reyes BA, Van Bockstaele EJ, Strayer DS. HIV-1 Tat neurotoxicity: a model of acute and chronic exposure, and neuroprotection by gene delivery of antioxidant enzymes. Neurobiol Dis. 2012 Feb;45 (2):657-70.

[66] Gannon P, Khan MZ, Kolson DL. Current understanding of HIV-associated neurocognitive disorders pathogenesis. Curr Opin Neurol. (Research Support, N.I.H., ExtramuralReview). 2011 Jun;24 (3):275-83.

[67] Rao JS, Kim HW, Kellom M, Greenstein D, Chen M, Kraft AD, et al. Increased neuroinflammatory and arachidonic acid cascade markers, and reduced synaptic proteins, in brain of HIV-1 transgenic rats. J Neuroinflammation. 2011;8:101.

[68] Kusao I, Shiramizu B, Liang CY, Grove J, Agsalda M, Troelstrup D, et al. Cognitive performance related to HIV-1-infected monocytes. J Neuropsychiatry Clin Neurosci. 2012 Dec 1;24 (1):71-80.

[69] Rostasy K, Monti L, Yiannoutsos C, Wu J, Bell J, Hedreen J, et al. NFkappaB activation, TNF-alpha expression, and apoptosis in the AIDS-Dementia-Complex. J Neurovirol. 2000 Dec;6 (6):537-43.

[70] Pemberton LA, Stone E, Price P, van Bockxmeer F, Brew BJ. The relationship between ApoE, TNFA, IL1a, IL1b and IL12b genes and HIV-1-associated dementia. HIV Med. 2008 Oct;9 (8):677-80.

[71] Lichtfuss GF, Cheng WJ, Farsakoglu Y, Paukovics G, Rajasuriar R, Velayudham P, et al. Virologically Suppressed HIV Patients Show Activation of NK Cells and Persistent Innate Immune Activation. J Immunol. 2012 Aug 1;189 (3):1491-9.

[72] Goldberg SH, van der Meer P, Hesselgesser J, Jaffer S, Kolson DL, Albright AV, et al. CXCR3 expression in human central nervous system diseases. Neuropathol Appl Neurobiol. 2001 Apr;27 (2):127-38.

[73] Letendre S, Zheng J, Kaul M, Yiannoutsos C, Ellis R, Taylor M, et al. Chemokines in cerebrospinal fluid correlate with cerebral metabolite patterns in HIV-infected individuals. Journal of NeuroVirology. 2011;17 (1):63-9. 
[74] Martin-Garcia J, Kolson DL, Gonzalez-Scarano F. Chemokine receptors in the brain: their role in HIV infection and pathogenesis. AIDS (London, England). 2002 Sep 6;16 (13):1709-30.

[75] van der Meer P, Ulrich AM, Gonzalez-Scarano F, Lavi E. Immunohistochemical analysis of CCR2, CCR3, CCR5, and CXCR4 in the human brain: potential mechanisms for HIV dementia. Exp Mol Pathol. 2000 Dec;69 (3):192-201.

[76] Dhillon NK, Williams R, Callen S, Zien C, Narayan O, Buch S. Roles of MCP-1 in development of HIV-dementia. Front Biosci. 2008;13:3913-8.

[77] Monteiro de Almeida S, Letendre S, Zimmerman J, Lazzaretto D, McCutchan A, Ellis R. Dynamics of monocyte chemoattractant protein type one (MCP-1) and HIV viral load in human cerebrospinal fluid and plasma. Journal of neuroimmunology. 2005 Dec;169 (1-2):144-52.

[78] Cartier L, Dubois-Dauphin M, Hartley O, Irminger-Finger I, Krause KH. Chemokineinduced cell death in CCR5-expressing neuroblastoma cells. Journal of neuroimmunology. 2003 Dec;145 (1-2):27-39.

[79] Kraft-Terry SD, Stothert AR, Buch S, Gendelman HE. HIV-1 neuroimmunity in the era of antiretroviral therapy. Neurobiol Dis. 2010 Mar;37 (3):542-8.

[80] Alirezaei M, Watry DD, Flynn CF, Kiosses WB, Masliah E, Williams BR, et al. Human immunodeficiency virus-1/surface glycoprotein 120 induces apoptosis through RNAactivated protein kinase signaling in neurons. J Neurosci. 2007 Oct 10;27 (41): 11047-55.

[81] O'Donnell LA, Agrawal A, Jordan-Sciutto KL, Dichter MA, Lynch DR, Kolson DL. Human immunodeficiency virus (HIV)-induced neurotoxicity: roles for the NMDA receptor subtypes. J Neurosci. 2006 Jan 18;26 (3):981-90.

[82] Abdulle S, Hagberg L, Gisslen M. Effects of antiretroviral treatment on blood-brain barrier integrity and intrathecal immunoglobulin production in neuroasymptomatic HIV-1-infected patients. HIV Med. 2005 May;6 (3):164-9.

[83] Kamat A, Lyons JL, Misra V, Uno H, Morgello S, Singer EJ, et al. Monocyte Activation Markers in Cerebrospinal Fluid Associated With Impaired Neurocognitive Testing in Advanced HIV Infection. Journal of acquired immune deficiency syndromes (1999). 2012 Jul 1;60 (3):234-43.

[84] Schellenberg AE, Buist R, Del Bigio MR, Khorooshi R, Toft-Hansen H, Owens T, et al. Blood-brain barrier disruption in CCL2 transgenic mice during pertussis toxin-induced brain inflammation. Fluids and barriers of the CNS. 2012 Apr 30;9 (1):10.

[85] Eugenin EA, Osiecki K, Lopez L, Goldstein H, Calderon TM, Berman JW. CCL2/ monocyte chemoattractant protein-1 mediates enhanced transmigration of human immunodeficiency virus (HIV)-infected leukocytes across the blood-brain barrier: a potential mechanism of HIV-CNS invasion and NeuroAIDS. J Neurosci. (Compara- 
tive StudyResearch Support, N.I.H., ExtramuralResearch Support, Non-U.S. Gov't). 2006 Jan 25;26 (4):1098-106.

[86] Roberts TK, Eugenin EA, Lopez L, Romero IA, Weksler BB, Couraud PO, et al. CCL2 disrupts the adherens junction: implications for neuroinflammation. Lab Invest. 2012 Aug;92 (8):1213-33.

[87] Lu SM, Tremblay ME, King IL, Qi J, Reynolds HM, Marker DF, et al. HIV-1 Tat-induced microgliosis and synaptic damage via interactions between peripheral and central myeloid cells. PLoS One. 2011;6 (9):e23915.

[88] Markowitz AJ, White MG, Kolson DL, Jordan-Sciutto KL. Cellular interplay between neurons and glia: toward a comprehensive mechanism for excitotoxic neuronal loss in neurodegeneration. Cellscience. 2007 Jul 27;4 (1):111-46.

[89] Benos DJ, Hahn BH, Bubien JK, Ghosh SK, Mashburn NA, Chaikin MA, et al. Envelope glycoprotein gp120 of human immunodeficiency virus type 1 alters ion transport in astrocytes: implications for AIDS dementia complex. Proc Natl Acad Sci U S A. 1994 Jan 18;91 (2):494-8.

[90] Kolson DL, Buchhalter J, Collman R, Hellmig B, Farrell CF, Debouck C, et al. HIV-1 Tat alters normal organization of neurons and astrocytes in primary rodent brain cell cultures: RGD sequence dependence. AIDS Res Hum Retroviruses. 1993 Jul;9 (7): 677-85.

[91] Reddy PV, Gandhi N, Samikkannu T, Saiyed Z, Agudelo M, Yndart A, et al. HIV-1 gp120 induces antioxidant response element-mediated expression in primary astrocytes: Role in HIV associated neurocognitive disorder. Neurochem Int. 2011 Jul 3.

[92] Shukla V, Mishra SK, Pant HC. Oxidative stress in neurodegeneration. Adv Pharmacol Sci. 2011;2011:572634.

[93] Reynolds A, Laurie C, Mosley RL, Gendelman HE. Oxidative stress and the pathogenesis of neurodegenerative disorders. Int Rev Neurobiol. 2007;82:297-325.

[94] Melo A, Monteiro L, Lima RM, Oliveira DM, Cerqueira MD, El-Bacha RS. Oxidative stress in neurodegenerative diseases: mechanisms and therapeutic perspectives. Oxid Med Cell Longev. 2011;2011:467180.

[95] Ramsey C, Glass CA, Montgomery MB, Lindl KA, Ritson GP, Chia LA, Hamilton RL, Chu CT, Jordan-Sciutto KL. Expression of Nrf2 in Neurodegenerative Diseases. J Neuropathol Exp Neurol. 2007;66 (1):75-85.

[96] Lipton S. Update on current models of HIV-related neuronal injury: platelet-activating factor, arachidonic acid, and nitric oxide. Adv Neuroimmunol. 1994;4 (3):181-8.

[97] Mondal D, Pradhan L, Ali M, Agrawal KC. HAART drugs induce oxidative stress in human endothelial cells and increase endothelial recruitment of mononuclear cells: exacerbation by inflammatory cytokines and amelioration by antioxidants. Cardiovasc Toxicol. 2004;4 (3):287-302. 
[98] Lagathu C, Eustace B, Prot M, Frantz D, Gu Y, Bastard JP, et al. Some HIV antiretrovirals increase oxidative stress and alter chemokine, cytokine or adiponectin production in human adipocytes and macrophages. Antivir Ther. 2007;12 (4):489-500.

[99] Chandra S, Mondal D, Agrawal KC. HIV-1 protease inhibitor induced oxidative stress suppresses glucose stimulated insulin release: protection with thymoquinone. Exp Biol Med (Maywood). 2009 Apr;234 (4):442-53.

[100] Walsh KA, Megyesi JF, Wilson JX, Crukley J, Laubach VE, Hammond RR. Antioxidant protection from HIV-1 gp120-induced neuroglial toxicity. J Neuroinflammation. 2004 May 27;1 (1):8.

[101] Cherry CL, Duncan AJ, Mackie KF, Wesselingh SL, Brew BJ. A Report on the Effect of Commencing Enfuvirtide on Peripheral Neuropathy. AIDS Research and Human Retroviruses. 2008;24 (8):1027-30.

[102] Blas-Garcia A, Apostolova N, Esplugues JV. Oxidative stress and mitochondrial impairment after treatment with anti-HIV drugs: clinical implications. Curr Pharm Des. 2011 Dec 1;17 (36):4076-86.

[103] Hulgan T, Morrow J, D'Aquila RT, Raffanti S, Morgan M, Rebeiro P, et al. Oxidant stress is increased during treatment of human immunodeficiency virus infection. Clin Infect Dis. 2003 Dec 15;37 (12):1711-7.

[104] Mandas A, Iorio EL, Congiu MG, Balestrieri C, Mereu A, Cau D, et al. Oxidative imbalance in HIV-1 infected patients treated with antiretroviral therapy. Journal of biomedicine \& biotechnology. 2009;2009:749575.

[105] Calkins M, Johnson DA, Townsend JA, Vargas MR, Dowell JA, Williamson TP, Kraft AD, Lee JM, Li J, Johnson JA. The Nrf2/ARE Pathway as a Potential Therapeutic Target in Neurodegenerative Disease. Antiox Redox Sig. 2009;11 (3):497-508.

[106] Sonnerborg A, Carlin G, Akerlund B, Jarstrand C. Increased production of malondialdehyde in patients with HIV infection. Scand J Infect Dis. 1988;20 (3):287-90.

[107] Moore K, Roberts LJ, 2nd. Measurement of lipid peroxidation. Free radical research. 1998 Jun;28 (6):659-71.

[108] McLemore JL, Beeley P, Thorton K, Morrisroe K, Blackwell W, Dasgupta A. Rapid automated determination of lipid hydroperoxide concentrations and total antioxidant status of serum samples from patients infected with HIV: elevated lipid hydroperoxide concentrations and depleted total antioxidant capacity of serum samples. Am J Clin Pathol. 1998 Mar;109 (3):268-73.

[109] Favier A, Sappey C, Leclerc P, Faure P, Micoud M. Antioxidant status and lipid peroxidation in patients infected with HIV. Chem Biol Interact. 1994 Jun;91 (2-3):165-80.

[110] Allard JP, Aghdassi E, Chau J, Salit I, Walmsley S. Oxidative stress and plasma antioxidant micronutrients in humans with HIV infection. Am J Clin Nutr. 1998 Jan;67 (1):143-7. 
[111] Malvy DJ, Richard MJ, Arnaud J, Favier A, Amedee-Manesme O. Relationship of plasma malondialdehyde, vitamin E and antioxidant micronutrients to human immunodeficiency virus-1 seropositivity. Clin Chim Acta. 1994 Jan 14;224 (1):89-94.

[112] Walmsley SL, Winn LM, Harrison ML, Uetrecht JP, Wells PG. Oxidative stress and thiol depletion in plasma and peripheral blood lymphocytes from HIV-infected patients: toxicological and pathological implications. AIDS (London, England). 1997 Nov 15;11 (14):1689-97.

[113] Jareno EJ, Bosch-Morell F, Fernandez-Delgado R, Donat J, Romero FJ. Serum malondialdehyde in HIV seropositive children. Free Radic Biol Med. 1998 Feb;24 (3):503-6.

[114] Repetto M, Reides C, Gomez Carretero ML, Costa M, Griemberg G, Llesuy S. Oxidative stress in blood of HIV infected patients. Clin Chim Acta. 1996 Nov 29;255 (2): 107-17.

[115] Sacktor N, Haughey N, Cutler R, Tamara A, Turchan J, Pardo C, Vargas D, Nath A. Novel markers of oxidative stress in actively progressive HIV dementia. Journal of neuroimmunology. 2004;157:176-84.

[116] Haughey NJ, Cutler RG, Tamara A, McArthur JC, Vargas DL, Pardo CA, et al. Perturbation of sphingolipid metabolism and ceramide production in HIV-dementia. Ann Neurol. 2004 Feb;55 (2):257-67.

[117] Turchan J, Pocernich CB, Gairola C, Chauhan A, Schifitto G, Butterfield DA, Buch S, Narayan O, Sinai A, Geiger J, Berger JR, Elford H, Nath A. Oxidative stress in HIV demented patients and protection ex vivo with novel antioxidants. Neurology. 2003;60:307-14.

[118] Suresh DR, Annam V, Pratibha K, Prasad BV. Total antioxidant capacity--a novel early bio-chemical marker of oxidative stress in HIV infected individuals. J Biomed Sci. 2009;16:61.

[119] Haughey NJ, Steiner J, Nath A, McArthur JC, Sacktor N, Pardo C, et al. Converging roles for sphingolipids and cell stress in the progression of neuro-AIDS. Front Biosci. 2008;13:5120-30.

[120] Droge W, Eck HP, Mihm S. Oxidant-antioxidant status in human immunodeficiency virus infection. Methods Enzymol. 1994;233:594-601.

[121] Ogunro PS, Ogungbamigbe TO, Elemie PO, Egbewale BE, Adewole TA. Plasma selenium concentration and glutathione peroxidase activity in HIV-1/AIDS infected patients: a correlation with the disease progression. Niger Postgrad Med J. 2006 Mar;13 (1):1-5.

[122] Dworkin BM, Rosenthal WS, Wormser GP, Weiss L. Selenium deficiency in the acquired immunodeficiency syndrome. JPEN J Parenter Enteral Nutr. 1986 Jul-Aug;10 (4):405-7. 
[123] Sudfeld CR, Wang M, Aboud S, Giovannucci EL, Mugusi FM, Fawzi WW. Vitamin D and HIV Progression among Tanzanian Adults Initiating Antiretroviral Therapy. PLoS ONE. 2012;7 (6):e40036.

[124] Srinivas A, Dias BF. Antioxidants in HIV positive children. Indian J Pediatr. 2008 Apr;75 (4):347-50.

[125] Bilbis LS, Idowu DB, Saidu Y, Lawal M, Njoku CH. Serum levels of antioxidant vitamins and mineral elements of human immunodeficiency virus positive subjects in Sokoto, Nigeria. Ann Afr Med. 2010 Oct-Dec;9 (4):235-9.

[126] Oliveira KF, Cunha DF, Weffort VR. Analysis of serum and supplemented vitamin C and oxidative stress in HIV-infected children and adolescents. J Pediatr (Rio J). 2011 Nov-Dec;87 (6):517-22.

[127] Delmas-Beauvieux MC, Peuchant E, Couchouron A, Constans J, Sergeant C, Simonoff $\mathrm{M}$, et al. The enzymatic antioxidant system in blood and glutathione status in human immunodeficiency virus (HIV)-infected patients: effects of supplementation with selenium or beta-carotene. Am J Clin Nutr. 1996 Jul;64 (1):101-7.

[128] Boven LA, Gomes L, Hery C, Gray F, Verhoef J, Portegies P, et al. Increased peroxynitrite activity in AIDS dementia complex: implications for the neuropathogenesis of HIV-1 infection. J Immunol. (Research Support, Non-U.S. Gov't). 1999 Apr 1;162 (7): 4319-27.

[129] Aukrust P, Svardal AM, Muller F, Lunden B, Berge RK, Ueland PM, et al. Increased levels of oxidized glutathione in CD4+ lymphocytes associated with disturbed intracellular redox balance in human immunodeficiency virus type 1 infection. Blood. 1995 Jul 1;86 (1):258-67.

[130] Buhl R, Jaffe HA, Holroyd KJ, Wells FB, Mastrangeli A, Saltini C, et al. Systemic glutathione deficiency in symptom-free HIV-seropositive individuals. Lancet. 1989 Dec 2;2 (8675):1294-8.

[131] Jaruga P, Jaruga B, Olczak A, Halota W, Olinski R. Oxidative DNA base damage in lymphocytes of HIV-infected drug users. Free radical research. 1999 Sep;31 (3): 197-200.

[132] Roc AC, Ances BM, Chawla S, Korczykowski M, Wolf RL, Kolson DL, et al. Detection of Human Immunodeficiency Virus Induced Inflammation and Oxidative Stress in Lenticular Nuclei With Magnetic Resonance Spectroscopy Despite Antiretroviral Therapy. 2007. p. 1249-57.

[133] Wanchu A, Rana SV, Pallikkuth S, Sachdeva RK. Short communication: oxidative stress in HIV-infected individuals: a cross-sectional study. AIDS Res Hum Retroviruses. 2009 Dec;25 (12):1307-11.

[134] Flourie F, Arab K, Gagnieu MC, Tardy JC, Jeanblanc F, Livrozet JM, et al. (Redox status in HIV+ patients under HAART). Ann Biol Clin (Paris). 2004 Nov-Dec;62 (6): 713-5. 
[135] Gil L, Tarinas A, Hernandez D, Riveron BV, Perez D, Tapanes R, et al. Altered oxidative stress indexes related to disease progression marker in human immunodeficiency virus infected patients with antiretroviral therapy. Biomed Pharmacother. 2010 Sep 25.

[136] Ibeh BO, Obidoa O, Nwuke C. Lipid Peroxidation Correlates with HIVmRNA in Serodiscordant Heterosexual HIVpartners of Nigerian Origin. Indian J Clin Biochem. 2011 Jul;26 (3):249-56.

[137] Ibeh BO, Emeka-Nwabunnia IK. Increased oxidative stress condition found in different stages of HIV disease in patients undergoing antiretroviral therapy in Umuahia (Nigeria). Immunopharmacol Immunotoxicol. 2012 Apr 28.

[138] Masia M, Padilla S, Bernal E, Almenar MV, Molina J, Hernandez I, et al. Influence of antiretroviral therapy on oxidative stress and cardiovascular risk: a prospective cross-sectional study in HIV-infected patients. Clin Ther. 2007 Jul;29 (7):1448-55.

[139] Ngondi JL, Oben J, Forkah DM, Etame LH, Mbanya D. The effect of different combination therapies on oxidative stress markers in HIV infected patients in Cameroon. AIDS Res Ther. 2006;3:19.

[140] Hurwitz BE, Klimas NG, Llabre MM, Maher KJ, Skyler JS, Bilsker MS, et al. HIV, metabolic syndrome $\mathrm{X}$, inflammation, oxidative stress, and coronary heart disease risk : role of protease inhibitor exposure. Cardiovasc Toxicol. 2004;4 (3):303-16.

[141] Stephensen CB, Marquis GS, Jacob RA, Kruzich LA, Douglas SD, Wilson CM. Vitamins $\mathrm{C}$ and $\mathrm{E}$ in adolescents and young adults with HIV infection. Am J Clin Nutr. 2006 Apr;83 (4):870-9.

[142] Stephensen CB, Marquis GS, Douglas SD, Kruzich LA, Wilson CM. Glutathione, glutathione peroxidase, and selenium status in HIV-positive and HIV-negative adolescents and young adults. Am J Clin Nutr. 2007 Jan;85 (1):173-81.

[143] Sundaram M, Saghayam S, Priya B, Venkatesh KK, Balakrishnan P, Shankar EM, et al. Changes in antioxidant profile among HIV-infected individuals on generic highly active antiretroviral therapy in southern India. Int J Infect Dis. 2008 Nov;12 (6):e61-6.

[144] Padmanabhan V, Rai K, Hegde AM, Shetty S. Total antioxidant capacity of saliva in children with HIV. J Clin Pediatr Dent. 2010 Summer;34 (4):347-50.

[145] Awodele O, Olayemi SO, Nwite JA, Adeyemo TA. Investigation of the levels of oxidative stress parameters in HIV and HIV-TB co-infected patients. J Infect Dev Ctries. 2012 Jan;6 (1):79-85.

[146] Paul S, Bogdanov MB, Matson WR, Metakis L, Jacobs J, Beal MF. Urinary 8-hydroxy-2'-deoxyguanosine, a metabolite of oxidized DNA, is not elevated in HIV patients on combination antiretroviral therapy. Free radical research. 2003 May;37 (5): 499-502. 
[147] Zhang Y, Wang M, Li H, Zhang H, Shi Y, Wei F, et al. Accumulation of nuclear and mitochondrial DNA damage in the frontal cortex cells of patients with HIV-associated neurocognitive disorders. Brain Res. 2012 Jun 6;1458:1-11.

[148] Edeas MA, Emerit I, Khalfoun Y, Lazizi Y, Cernjavski L, Levy A, et al. Clastogenic factors in plasma of HIV-1 infected patients activate HIV-1 replication in vitro: inhibition by superoxide dismutase. Free Radic Biol Med. 1997;23 (4):571-8.

[149] Kimura T, Kameoka M, Ikuta K. Amplification of superoxide anion generation in phagocytic cells by HIV-1 infection. FEBS letters. 1993 Jul 12;326 (1-3):232-6.

[150] Mollace V, Salvemini D, Riley DP, Muscoli C, Iannone M, Granato T, et al. The contribution of oxidative stress in apoptosis of human-cultured astroglial cells induced by supernatants of HIV-1-infected macrophages. J Leukoc Biol. 2002 Jan;71 (1):65-72.

[151] Bukrinsky MI, Nottet HS, Schmidtmayerova H, Dubrovsky L, Flanagan CR, Mullins $\mathrm{ME}$, et al. Regulation of nitric oxide synthase activity in human immunodeficiency virus type 1 (HIV-1)-infected monocytes: implications for HIV-associated neurological disease. J Exp Med. 1995 Feb 1;181 (2):735-45.

[152] Piette J, Legrand-Poels S. HIV-1 reactivation after an oxidative stress mediated by different reactive oxygen species. Chem Biol Interact. 1994 Jun;91 (2-3):79-89.

[153] Szydlowska K, Tymianski M. Calcium, ischemia and excitotoxicity. Cell Calcium. 2010 Feb;47 (2):122-9.

[154] Jiang ZG, Piggee C, Heyes MP, Murphy C, Quearry B, Bauer M, et al. Glutamate is a mediator of neurotoxicity in secretions of activated HIV-1-infected macrophages. Journal of neuroimmunology. 2001 Jul 2;117 (1-2):97-107.

[155] Erdmann N, Zhao J, Lopez AL, Herek S, Curthoys N, Hexum TD, et al. Glutamate production by HIV-1 infected human macrophage is blocked by the inhibition of glutaminase. J Neurochem. 2007 Jul;102 (2):539-49.

[156] Zhao J, Lopez AL, Erichsen D, Herek S, Cotter RL, Curthoys NP, et al. Mitochondrial glutaminase enhances extracellular glutamate production in HIV-1-infected macrophages: linkage to HIV-1 associated dementia. J Neurochem. 2004 Jan;88 (1):169-80.

[157] Huang Y, Zhao L, Jia B, Wu L, Li Y, Curthoys N, et al. Glutaminase dysregulation in HIV-1-infected human microglia mediates neurotoxicity: relevant to HIV-1-associated neurocognitive disorders. J Neurosci. 2011 Oct 19;31 (42):15195-204.

[158] Banerjee A, Zhang X, Manda KR, Banks WA, Ercal N. HIV proteins (gp120 and Tat) and methamphetamine in oxidative stress-induced damage in the brain: potential role of the thiol antioxidant N-acetylcysteine amide. Free Radic Biol Med. 2010 May 15;48 (10):1388-98.

[159] Price TO, Ercal N, Nakaoke R, Banks WA. HIV-1 viral proteins gp120 and Tat induce oxidative stress in brain endothelial cells. Brain Res. 2005 May 31;1045 (1-2):57-63. 
[160] Viviani B, Corsini E, Binaglia M, Galli CL, Marinovich M. Reactive oxygen species generated by glia are responsible for neuron death induced by human immunodeficiency virus-glycoprotein 120 in vitro. Neuroscience. 2001;107 (1):51-8.

[161] Dawson VL, Dawson TM, Uhl GR, Snyder SH. Human immunodeficiency virus type 1 coat protein neurotoxicity mediated by nitric oxide in primary cortical cultures. Proc Natl Acad Sci U S A. 1993 Apr 15;90 (8):3256-9.

[162] Pietraforte D, Tritarelli E, Testa U, Minetti M. gp120 HIV envelope glycoprotein increases the production of nitric oxide in human monocyte-derived macrophages. J Leukoc Biol. 1994 Feb;55 (2):175-82.

[163] Kruman, II, Nath A, Mattson MP. HIV-1 protein Tat induces apoptosis of hippocampal neurons by a mechanism involving caspase activation, calcium overload, and oxidative stress. Exp Neurol. 1998 Dec;154 (2):276-88.

[164] Toborek M, Lee YW, Pu H, Malecki A, Flora G, Garrido R, et al. HIV-Tat protein induces oxidative and inflammatory pathways in brain endothelium. J Neurochem. 2003 Jan;84 (1):169-79.

[165] Israel N, Gougerot-Pocidalo MA. Oxidative stress in human immunodeficiency virus infection. Cell Mol Life Sci. 1997 Dec;53 (11-12):864-70.

[166] Flores SC, Marecki JC, Harper KP, Bose SK, Nelson SK, McCord JM. Tat protein of human immunodeficiency virus type 1 represses expression of manganese superoxide dismutase in HeLa cells. Proc Natl Acad Sci U S A. 1993 Aug 15;90 (16):7632-6.

[167] Aksenov MY, Hasselrot U, Bansal AK, Wu G, Nath A, Anderson C, et al. Oxidative damage induced by the injection of HIV-1 Tat protein in the rat striatum. Neurosci Lett. 2001 Jun 1;305 (1):5-8.

[168] Raidel SM, Haase C, Jansen NR, Russ RB, Sutliff RL, Velsor LW, et al. Targeted myocardial transgenic expression of HIV Tat causes cardiomyopathy and mitochondrial damage. Am J Physiol Heart Circ Physiol. 2002 May;282 (5):H1672-8.

[169] Choi J, Liu RM, Kundu RK, Sangiorgi F, Wu W, Maxson R, et al. Molecular mechanism of decreased glutathione content in human immunodeficiency virus type 1 Tattransgenic mice. J Biol Chem. 2000 Feb 4;275 (5):3693-8.

[170] Westendorp MO, Shatrov VA, Schulze-Osthoff K, Frank R, Kraft M, Los M, et al. HIV-1 Tat potentiates TNF-induced NF-kappa B activation and cytotoxicity by altering the cellular redox state. The EMBO journal. 1995 Feb 1;14 (3):546-54.

[171] Deshmane SL, Mukerjee R, Fan S, Del Valle L, Michiels C, Sweet T, et al. Activation of the oxidative stress pathway by HIV-1 Vpr leads to induction of hypoxia-inducible factor 1alpha expression. J Biol Chem. 2009 Apr 24;284 (17):11364-73.

[172] Ferrucci A, Nonnemacher MR, Cohen EA, Wigdahl B. Extracellular human immunodeficiency virus type 1 viral protein $R$ causes reductions in astrocytic ATP and glutathione levels compromising the antioxidant reservoir. Virus Res. 2012 Jun 9. 
[173] Vidal F, Gutierrez F, Gutierrez M, Olona M, Sanchez V, Mateo G, et al. Pharmacogenetics of adverse effects due to antiretroviral drugs. AIDS reviews. (Research Support, Non-U.S. Gov'tReview). 2010 Jan-Mar;12 (1):15-30.

[174] Zhou H, Gurley EC, Jarujaron S, Ding H, Fang Y, Xu Z, Pandak WM, Hylemon PB. HIV protease inhibitors activate the unfolded protein response and disrupt lipid metabolism in primary hepatocytes. Am J Physiol Gastrointest Liver Physiol. 2006;291:G1071-G80.

[175] Zhou H, Pandak WM, Lyall V, Natarajan R, Hylemon PB. HIV Protease Inhibitors Activate the Unfolded Protein Response in Macrophages: Implication for Atherosclerosis and Cardiovascular Disease. Mol Pharmacol. 2005;68:690-700.

[176] Letendre S, Marquie-Beck J, Capparelli E, Best B, Clifford D, Collier AC, et al. Validation of the CNS Penetration-Effectiveness rank for quantifying antiretroviral penetration into the central nervous system. Arch Neurol. 2008 Jan;65 (1):65-70.

[177] Letendre SL, Ellis RJ, Ances BM, McCutchan JA. Neurologic complications of HIV disease and their treatment. Top HIV Med. 2010 Apr-May;18 (2):45-55.

[178] Tozzi V, Balestra P, Salvatori MF, Vlassi C, Liuzzi G, Giancola ML, et al. Changes in Cognition During Antiretroviral Therapy: Comparison of 2 Different Ranking Systems to Measure Antiretroviral Drug Efficacy on HIV-Associated Neurocognitive Disorders. JAIDS Journal of Acquired Immune Deficiency Syndromes. 2009;52 (1): 56-63 10.1097/QAI.0b013e3181af83d6.

[179] Garvey L, Winston A, Walsh J, Post F, Porter K, Gazzard B, et al. Antiretroviral therapy CNS penetration and HIV-1-associated CNS disease. Neurology. 2011 Feb 22;76 (8):693-700.

[180] Lanoy E, Guiguet M, Bentata M, Rouveix E, Dhiver C, Poizot-Martin I, et al. Survival after neuroAIDS. Neurology. 2011 February 15, 2011;76 (7):644-51.

[181] Marra CM, Zhao Y, Clifford DB, Letendre S, Evans S, Henry K, et al. Impact of combination antiretroviral therapy on cerebrospinal fluid HIV RNA and neurocognitive performance. AIDS (London, England). 2009 Jul 17;23 (11):1359-66.

[182] Smurzynski M, Wu K, Letendre S, Robertson K, Bosch RJ, Clifford DB, et al. Effects of central nervous system antiretroviral penetration on cognitive functioning in the ALLRT cohort. AIDS (London, England). 2011;25 (3):357-65 10.1097/QAD. Ob013e32834171f8.

[183] Cysique LA, Vaida F, Letendre S, Gibson S, Cherner M, Woods SP, et al. Dynamics of cognitive change in impaired HIV-positive patients initiating antiretroviral therapy. Neurology. 2009 August 4, 2009;73 (5):342-8.

[184] Marra CM, Zhao Y, Clifford DB, Letendre S, Evans S, Henry K, et al. Impact of combination antiretroviral therapy on cerebrospinal fluid HIV RNA and neurocognitive performance. AIDS. 2009 Jul 17;23(11):1359-66. 
[185] Ramirez SH, Potula R, Fan S, Eidem T, Papugani A, Reichenbach N, et al. Methamphetamine disrupts blood-brain barrier function by induction of oxidative stress in brain endothelial cells. J Cereb Blood Flow Metab. 2009 Dec;29 (12):1933-45.

[186] Shiu C, Barbier E, Di Cello F, Choi HJ, Stins M. HIV-1 gp120 as well as alcohol affect blood-brain barrier permeability and stress fiber formation: involvement of reactive oxygen species. Alcohol Clin Exp Res. 2007 Jan;31 (1):130-7.

[187] Qin L, He J, Hanes RN, Pluzarev O, Hong JS, Crews FT. Increased systemic and brain cytokine production and neuroinflammation by endotoxin following ethanol treatment. J Neuroinflammation. 2008;5:10.

[188] Ferraresi R, Troiano L, Roat E, Nemes E, Lugli E, Nasi M, et al. Protective effect of acetyl-L-carnitine against oxidative stress induced by antiretroviral drugs. FEBS letters. 2006 Dec 11;580 (28-29):6612-6.

[189] Manda K, Banerjee A, Banks WA, Ercal N. Highly active antiretroviral therapy drug combination induces oxidative stress and mitochondrial dysfunction in immortalized human blood-brain barrier endothelial cells. Free Rad Biol and Med. 2011;50:801-10.

[190] Brandmann M, Tulpule K, Schmidt MM, Dringen R. The antiretroviral protease inhibitors indinavir and nelfinavir stimulate Mrp1-mediated GSH export from cultured brain astrocytes. J Neurochem. 2012 Jan;120 (1):78-92.

[191] Touzet O, Philips A. Resveratrol protects against protease inhibitor-induced reactive oxygen species production, reticulum stress and lipid raft perturbation. AIDS (London, England). 2010 Jun 19, 2010;24 (10):1437-47.

[192] Lewis W, Gonzalez B, Chomyn A, Papoian T. Zidovudine induces molecular, biochemical, and ultrastructural changes in rat skeletal muscle mitochondria. J Clin Invest. 1992 Apr;89 (4):1354-60.

[193] Gao RY, Mukhopadhyay P, Mohanraj R, Wang H, Horvath B, Yin S, et al. Resveratrol attenuates azidothymidine-induced cardiotoxicity by decreasing mitochondrial reactive oxygen species generation in human cardiomyocytes. Mol Med Report. 2011 JanFeb;4 (1):151-5.

[194] de la Asuncion JG, del Olmo ML, Sastre J, Pallardo FV, Vina J. Zidovudine (AZT) causes an oxidation of mitochondrial DNA in mouse liver. Hepatology. 1999 Mar;29 (3):985-7.

[195] de la Asuncion JG, Del Olmo ML, Gomez-Cambronero LG, Sastre J, Pallardo FV, Vina J. AZT induces oxidative damage to cardiac mitochondria: protective effect of vitamins C and E. Life Sci. 2004 Nov 19;76 (1):47-56.

[196] Bialkowska A, Bialkowski K, Gerschenson M, Diwan BA, Jones AB, Olivero OA, et al. Oxidative DNA damage in fetal tissues after transplacental exposure to 3'-azido-3'-deoxythymidine (AZT). Carcinogenesis. 2000 May;21 (5):1059-62. 
[197] Yamaguchi T, Katoh I, Kurata S. Azidothymidine causes functional and structural destruction of mitochondria, glutathione deficiency and HIV-1 promoter sensitization. Eur J Biochem. 2002 Jun;269 (11):2782-8.

[198] Velsor LW, Kovacevic M, Goldstein M, Leitner HM, Lewis W, Day BJ. Mitochondrial oxidative stress in human hepatoma cells exposed to stavudine. Toxicol Appl Pharmacol. 2004 Aug 15;199 (1):10-9.

[199] Gerschenson M, Nguyen VT, St Claire MC, Harbaugh SW, Harbaugh JW, Proia LA, et al. Chronic stavudine exposure induces hepatic mitochondrial toxicity in adult Erythrocebus patas monkeys. J Hum Virol. 2001 Nov-Dec;4 (6):335-42.

[200] Opii WO, Sultana R, Abdul HM, Ansari MA, Nath A, Butterfield DA. Oxidative stress and toxicity induced by the nucleoside reverse transcriptase inhibitor (NRTI)--2',3'-dideoxycytidine (ddC): relevance to HIV-dementia. Exp Neurol. 2007 Mar;204 (1):29-38.

[201] Apostolova N, Gomez-Sucerquia LJ, Moran A, Alvarez A, Blas-Garcia A, Esplugues JV. Enhanced oxidative stress and increased mitochondrial mass during efavirenz-induced apoptosis in human hepatic cells. Br J Pharmacol. 2010 Aug;160 (8):2069-84.

[202] Ciccarelli N, Fabbiani M, Di Giambenedetto S, Fanti I, Baldonero E, Bracciale L, et al. Efavirenz associated with cognitive disorders in otherwise asymptomatic HIV-infected patients. Neurology. 2011 Apr 19;76 (16):1403-9.

[203] Chai H, Yan S, Lin P, Lumsden AB, Yao Q, Chen C. Curcumin blocks HIV protease inhibitor ritonavir-induced vascular dysfunction in porcine coronary arteries. J Am Coll Surg. 2005 Jun;200 (6):820-30.

[204] Vincent S, Tourniaire F, El Yazidi CM, Compe E, Manches O, Plannels R, et al. Nelfinavir induces necrosis of 3T3F44-2A adipocytes by oxidative stress. Journal of acquired immune deficiency syndromes (1999). 2004 Dec 15;37 (5):1556-62.

[205] Amatore C, Arbault S, Jaouen G, Koh AC, Leong WK, Top S, et al. Pro-oxidant properties of AZT and other thymidine analogues in macrophages: implication of the azido moiety in oxidative stress. ChemMedChem. 2010 Feb 1;5 (2):296-301.

[206] Jensen BK, Akay C, Lindl KA, Jordan-Sciutto K. Involvement of the Antioxidant response pathway in neuroglial, neuronal, and astrocytic cultures exposed to antiretroviral compounds.. The International Symposium on NeuroVirology; New York, NY, USA. Journal of NeuroVirology2012. p. S51.

[207] Akay C, Cooper M, Odeleye A, Jensen BK, White M, Vassoler F, et al. Antiretroviral Drugs Induce Oxidative Stress and Neuronal Damage in the Central Nervous System. The International Symposium on NeuroVirology; 2012; New York, N.Y., USA: Journal of NeuroVirology; 2012. p. S5.

[208] Li W, Kong A. Molecular Mechanisms of Nrf2-Mediated Antioxidant Response. Molecular Carcinogenesis. 2009;48:91-104. 
[209] Shih A, Johnson DA, Wong G, Kraft AD, Jiang L, Erb H, Johnson JA, Murphy TH. Coordinate Regulation of Glutathione Biosynthesis and Release by Nrf2-Expressing Glia Potently Protects Neurons from Oxidative Stress. J Neurosci. 2003;23 (8): 3394-406.

[210] Cross SA, Cook DR, Chi AW, Vance PJ, Kolson LL, Wong BJ, et al. Dimethyl fumarate, an immune modulator and inducer of the antioxidant response, suppresses HIV replication and macrophage-mediated neurotoxicity: a novel candidate for HIV neuroprotection. J Immunol. (Research Support, N.I.H., Extramural). 2011 Nov 15;187 (10):5015-25.

[211] Weakley SM, Jiang J, Lu J, Wang X, Lin PH, Yao Q, et al. Natural antioxidant dihydroxybenzyl alcohol blocks ritonavir-induced endothelial dysfunction in porcine pulmonary arteries and human endothelial cells. Med Sci Monit. 2011 Sep;17 (9):BR235-41.

[212] Meulendyke KA, Pletnikov MV, Engle EL, Tarwater PM, Graham DR, Zink MC. Early minocycline treatment prevents a decrease in striatal dopamine in an SIV model of HIV-associated neurological disease. J Neuroimmune Pharmacol. 2012 Jun;7 (2): 454-64.

[213] Jariwalla RJ, Lalezari J, Cenko D, Mansour SE, Kumar A, Gangapurkar B, et al. Restoration of blood total glutathione status and lymphocyte function following alphalipoic acid supplementation in patients with HIV infection. J Altern Complement Med. 2008 Mar;14 (2):139-46.

[214] Batterham M, Gold J, Naidoo D, Lux O, Sadler S, Bridle S, et al. A preliminary open label dose comparison using an antioxidant regimen to determine the effect on viral load and oxidative stress in men with HIV/AIDS. Eur J Clin Nutr. 2001 Feb;55 (2): 107-14.

[215] Kutzing MK, Luo V, Firestein BL. Protection from glutamate-induced excitotoxicity by memantine. Ann Biomed Eng. 2012 May;40 (5):1170-81.

[216] Nagatsu T, Sawada M. Molecular mechanism of the relation of monoamine oxidase B and its inhibitors to Parkinson's disease: possible implications of glial cells. J Neural Transm Suppl. 2006 (71):53-65.

[217] Schifitto G, Yiannoutsos CT, Ernst T, Navia BA, Nath A, Sacktor N, et al. Selegiline and oxidative stress in HIV-associated cognitive impairment. Neurology. 2009 Dec 8;73 (23):1975-81.

[218] Bhaskaran K, Mussini C, Antinori A, Walker AS, Dorrucci M, Sabin C, et al. Changes in the incidence and predictors of human immunodeficiency virus-associated dementia in the era of highly active antiretroviral therapy. Ann Neurol. 2008 Feb;63 (2): 213-21.

[219] Nath A. Human immunodeficiency virus-associated neurocognitive disorder: pathophysiology in relation to drug addiction. Ann N Y Acad Sci. 2010 Feb;1187:122-8. 
[220] Cadet J, Krasnova I. Interactions of HIV and methamphetamine: Cellular and molecular mechanisms of toxicity potentiation. Neurotoxicity Research. 2007;12 (3):181-204.

[221] Durazzo TC, Rothlind JC, Cardenas VA, Studholme C, Weiner MW, Meyerhoff DJ. Chronic cigarette smoking and heavy drinking in human immunodeficiency virus: consequences for neurocognition and brain morphology. Alcohol. 2007 Nov;41 (7): 489-501.

[222] Miguez-Burbano MJ, Lewis JE, Moreno J, Fishman J. Cognitive performance and the thymus among HIV-infected subjects receiving HAART. Biologics. 2008 Jun;2 (2): 321-7.

[223] Miguez-Burbano MJ, Nair M, Lewis JE, Fishman J. The role of alcohol on platelets, thymus and cognitive performance among HIV-infected subjects: are they related? Platelets. 2009 Jun;20 (4):260-7.

[224] Winston A, Garvey L, Scotney E, Yerrakalva D, Allsop JM, Thomson EC, et al. Does acute hepatitis $C$ infection affect the central nervous system in HIV-1 infected individuals? J Viral Hepat. 2010 Jun;17 (6):419-26.

[225] Malaspina L, Woods SP, Moore DJ, Depp C, Letendre SL, Jeste D, et al. Successful cognitive aging in persons living with HIV infection. J Neurovirol. Feb;17 (1):110-9.

[226] Mateen FJ, Mills EJ. Aging and HIV-related cognitive loss. Jama. Jul 25;308 (4):349-50.

[227] Deeks SG. Immune dysfunction, inflammation, and accelerated aging in patients on antiretroviral therapy. Top HIV Med. 2009 Sep-Oct;17 (4):118-23.

[228] Xu J, Ikezu T. The comorbidity of HIV-associated neurocognitive disorders and Alzheimer's disease: a foreseeable medical challenge in post-HAART era. J Neuroimmune Pharmacol. 2009 Jun;4 (2):200-12.

[229] Tisch S, Brew B. Parkinsonism in hiv-infected patients on highly active antiretroviral therapy. Neurology. 2009 Aug 4;73 (5):401-3.

[230] Alisky JM. The coming problem of HIV-associated Alzheimer's disease. Medical hypotheses. 2007;69 (5):1140-3.

[231] Holt JL, Kraft-Terry SD, Chang L. Neuroimaging studies of the aging HIV-1-infected brain. J Neurovirol. Aug;18 (4):291-302.

[232] Gannon P, Khan MZ, Kolson DL. Current understanding of HIV-associated neurocognitive disorders pathogenesis. Curr Opin Neurol. Jun;24 (3):275-83.

[233] Anthony ICB, J.E. Neuropathological Findings Associated with Long-Term HAART. In: Paul RS, NC; Valcour, V; Tasima, KT, editor. HIV and the Brain: New Challenges in the Modern Era: Humana Press; 2009. p. 1-19.

[234] Brew BJ, Crowe SM, Landay A, Cysique LA, Guillemin G. Neurodegeneration and ageing in the HAART era. J Neuroimmune Pharmacol. 2009 Jun;4 (2):163-74. 
[235] Sacktor N, Lyles RH, Skolasky R, Kleeberger C, Selnes OA, Miller EN, et al. HIV-associated neurologic disease incidence changes:: Multicenter AIDS Cohort Study, 1990-1998. Neurology. 2001 Jan 23;56 (2):257-60.

[236] Martin CP, Fain MJ, Klotz SA. The older HIV-positive adult: a critical review of the medical literature. Am J Med. 2008 Dec;121 (12):1032-7.

[237] Kalayjian RC, Landay A, Pollard RB, Taub DD, Gross BH, Francis IR, et al. Age-related immune dysfunction in health and in human immunodeficiency virus (HIV) disease: association of age and HIV infection with naive CD8+ cell depletion, reduced expression of CD28 on CD8+ cells, and reduced thymic volumes. J Infect Dis. 2003 Jun 15;187 (12):1924-33.

[238] Kirk JB, Goetz MB. Human immunodeficiency virus in an aging population, a complication of success. Journal of the American Geriatrics Society. 2009 Nov;57 (11): 2129-38.

[239] Butt AA, Dascomb KK, DeSalvo KB, Bazzano L, Kissinger PJ, Szerlip HM. Human immunodeficiency virus infection in elderly patients. Southern medical journal. 2001 Apr;94 (4):397-400.

[240] Manfredi R. HIV disease and advanced age: an increasing therapeutic challenge. Drugs \& aging. 2002;19 (9):647-69.

[241] Goetz MB, Boscardin WJ, Wiley D, Alkasspooles S. Decreased recovery of CD4 lymphocytes in older HIV-infected patients beginning highly active antiretroviral therapy. AIDS (London, England). 2001 Aug 17;15 (12):1576-9.

[242] Thompson MA, Aberg JA, Cahn P, Montaner JS, Rizzardini G, Telenti A, et al. Antiretroviral treatment of adult HIV infection: 2010 recommendations of the International AIDS Society-USA panel. Jama. Jul 21;304 (3):321-33.

[243] Spengler U. Management of end-stage liver disease in HIV/hepatitis C virus co-infection. Curr Opin HIV AIDS. Nov;6 (6):527-33.

[244] Desquilbet L, Jacobson LP, Fried LP, Phair JP, Jamieson BD, Holloway M, et al. HIV-1 infection is associated with an earlier occurrence of a phenotype related to frailty. The journals of gerontology. 2007 Nov;62 (11):1279-86.

[245] Patel P, Hanson DL, Sullivan PS, Novak RM, Moorman AC, Tong TC, et al. Incidence of types of cancer among HIV-infected persons compared with the general population in the United States, 1992-2003. Ann Intern Med. 2008 May 20;148 (10):728-36.

[246] Zhou H, Pandak WM, Jr., Lyall V, Natarajan R, Hylemon PB. HIV protease inhibitors activate the unfolded protein response in macrophages: implication for atherosclerosis and cardiovascular disease. Molecular pharmacology. 2005 Sep;68 (3):690-700.

[247] Bozzette SA, Ake CF, Tam HK, Chang SW, Louis TA. Cardiovascular and cerebrovascular events in patients treated for human immunodeficiency virus infection. The New England journal of medicine. 2003 Feb 20;348 (8):702-10. 
[248] Cherner M, Ellis RJ, Lazzaretto D, Young C, Mindt MR, Atkinson JH, et al. Effects of HIV-1 infection and aging on neurobehavioral functioning: preliminary findings. AIDS (London, England). 2004 Jan 1;18 Suppl 1:S27-34.

[249] Sacktor N, Skolasky R, Selnes OA, Watters M, Poff P, Shiramizu B, et al. Neuropsychological test profile differences between young and old human immunodeficiency virus-positive individuals. J Neurovirol. 2007 Jun;13 (3):203-9.

[250] Chang L, Yakupov R, Nakama H, Stokes B, Ernst T. Antiretroviral treatment is associated with increased attentional load-dependent brain activation in HIV patients. J Neuroimmune Pharmacol. 2008 Jun;3 (2):95-104.

[251] Gongvatana A, Cohen RA, Correia S, Devlin KN, Miles J, Kang H, et al. Clinical contributors to cerebral white matter integrity in HIV-infected individuals. J Neurovirol. Oct;17 (5):477-86.

[252] Towgood KJ, Pitkanen M, Kulasegaram R, Fradera A, Kumar A, Soni S, et al. Mapping the brain in younger and older asymptomatic HIV-1 men: frontal volume changes in the absence of other cortical or diffusion tensor abnormalities. Cortex. Feb;48 (2):230-41.

[253] Ernst T, Chang L. Effect of aging on brain metabolism in antiretroviral-naive HIV patients. AIDS (London, England). 2004 Jan 1;18 Suppl 1:S61-7.

[254] Harezlak J, Buchthal S, Taylor M, Schifitto G, Zhong J, Daar E, et al. Persistence of HIV-associated cognitive impairment, inflammation, and neuronal injury in era of highly active antiretroviral treatment. AIDS (London, England). Mar 13;25 (5):625-33.

[255] Anthony IC, Ramage SN, Carnie FW, Simmonds P, Bell JE. Influence of HAART on HIV-related CNS disease and neuroinflammation. J Neuropathol Exp Neurol. 2005 Jun;64 (6):529-36.

[256] Brew BJ. Evidence for a change in AIDS dementia complex in the era of highly active antiretroviral therapy and the possibility of new forms of AIDS dementia complex. AIDS (London, England). 2004 Jan 1;18 Suppl 1:S75-8.

[257] Anthony IC, Ramage SN, Carnie FW, Simmonds P, Bell JE. Accelerated Tau deposition in the brains of individuals infected with human immunodeficiency virus-1 before and after the advent of highly active anti-retroviral therapy. Acta Neuropathol. 2006 Jun;111 (6):529-38.

[258] Ances BM, Benzinger TL, Christensen JJ, Thomas J, Venkat R, Teshome M, et al. 11CPiB imaging of human immunodeficiency virus-associated neurocognitive disorder. Arch Neurol. Jan;69 (1):72-7.

[259] Green DA, Masliah E, Vinters HV, Beizai P, Moore DJ, Achim CL. Brain deposition of beta-amyloid is a common pathologic feature in HIV positive patients. AIDS (London, England). 2005 Mar 4;19 (4):407-11. 
[260] Rempel HC, Pulliam L. HIV-1 Tat inhibits neprilysin and elevates amyloid beta. AIDS (London, England). 2005 Jan 28;19 (2):127-35.

[261] Brew BJ, Pemberton L, Blennow K, Wallin A, Hagberg L. CSF amyloid beta42 and tau levels correlate with AIDS dementia complex. Neurology. 2005 Nov 8;65 (9): 1490-2.

[262] Esiri MM, Biddolph SC, Morris CS. Prevalence of Alzheimer plaques in AIDS. J Neurol Neurosurg Psychiatry. 1998 Jul;65 (1):29-33.

[263] Cysique LA, Maruff P, Brew BJ. Prevalence and pattern of neuropsychological impairment in human immunodeficiency virus-infected/acquired immunodeficiency syndrome (HIV/AIDS) patients across pre- and post-highly active antiretroviral therapy eras: a combined study of two cohorts. J Neurovirol. 2004 Dec;10 (6):350-7.

[264] Cysique LA, Brew BJ. Neuropsychological functioning and antiretroviral treatment in HIV/AIDS: a review. Neuropsychol Rev. 2009 Jun;19 (2):169-85.

[265] Achim CL, Adame A, Dumaop W, Everall IP, Masliah E. Increased accumulation of intraneuronal amyloid beta in HIV-infected patients. J Neuroimmune Pharmacol. 2009 Jun;4 (2):190-9.

[266] Chen $\mathrm{CH}$, Vazquez-Padua M, Cheng YC. Effect of anti-human immunodeficiency virus nucleoside analogs on mitochondrial DNA and its implication for delayed toxicity. Mol Pharmacol. 1991 May;39 (5):625-8.

[267] Dalakas MC. Peripheral neuropathy and antiretroviral drugs. J Peripher Nerv Syst. 2001 Mar;6 (1):14-20.

[268] Schweinsburg BC, Taylor MJ, Alhassoon OM, Gonzalez R, Brown GG, Ellis RJ, et al. Brain mitochondrial injury in human immunodeficiency virus-seropositive (HIV+) individuals taking nucleoside reverse transcriptase inhibitors. J Neurovirol. 2005 Aug;11 (4):356-64.

[269] Dufer M, Neye Y, Krippeit-Drews P, Drews G. Direct interference of HIV protease inhibitors with pancreatic beta-cell function. Naunyn Schmiedebergs Arch Pharmacol. 2004 Jun;369 (6):583-90.

[270] Zhou H, Gurley EC, Jarujaron S, Ding H, Fang Y, Xu Z, et al. HIV protease inhibitors activate the unfolded protein response and disrupt lipid metabolism in primary hepatocytes. American journal of physiology. 2006 Dec;291 (6):G1071-80.

[271] Schutt M, Zhou J, Meier M, Klein HH. Long-term effects of HIV-1 protease inhibitors on insulin secretion and insulin signaling in INS-1 beta cells. J Endocrinol. 2004 Dec; 183 (3):445-54.

[272] Liang JS, Distler O, Cooper DA, Jamil H, Deckelbaum RJ, Ginsberg HN, et al. HIV protease inhibitors protect apolipoprotein $\mathrm{B}$ from degradation by the proteasome: a potential mechanism for protease inhibitor-induced hyperlipidemia. Nat Med. 2001 Dec;7 (12):1327-31. 
[273] Schubert M, Gautam D, Surjo D, Ueki K, Baudler S, Schubert D, et al. Role for neuronal insulin resistance in neurodegenerative diseases. Proc Natl Acad Sci U S A. 2004 Mar 2;101 (9):3100-5.

[274] Steen E, Terry BM, Rivera EJ, Cannon JL, Neely TR, Tavares R, et al. Impaired insulin and insulin-like growth factor expression and signaling mechanisms in Alzheimer's disease--is this type 3 diabetes? J Alzheimers Dis. 2005 Feb;7 (1):63-80.

[275] Kroner Z. The relationship between Alzheimer's disease and diabetes: Type 3 diabetes? Altern Med Rev. 2009 Dec;14 (4):373-9.

[276] Moyle G. Mechanisms of HIV and nucleoside reverse transcriptase inhibitor injury to mitochondria. Antivir Ther. 2005;10 Suppl 2:M47-52.

[277] Robertson KR, Smurzynski M, Parsons TD, Wu K, Bosch RJ, Wu J, et al. The prevalence and incidence of neurocognitive impairment in the HAART era. AIDS (London, England). 2007 Sep 12;21 (14):1915-21.

[278] Cook-Easterwood J, Middaugh LD, Griffin WC, 3rd, Khan I, Tyor WR. Highly active antiretroviral therapy of cognitive dysfunction and neuronal abnormalities in SCID mice with HIV encephalitis. Exp Neurol. 2007 Jun;205 (2):506-12.

[279] Heaton RK, Clifford DB, Franklin DR, Jr., Woods SP, Ake C, Vaida F, et al. HIV-associated neurocognitive disorders persist in the era of potent antiretroviral therapy: CHARTER Study. Neurology. 2010;75 (23):2087-96.

[280] Joska JA, Gouse H, Paul RH, Stein DJ, Flisher AJ. Does highly active antiretroviral therapy improve neurocognitive function? A systematic review. J Neurovirol. Mar;16 (2):101-14.

[281] Smurzynski M, Wu K, Letendre S, Robertson K, Bosch RJ, Clifford DB, et al. Effects of central nervous system antiretroviral penetration on cognitive functioning in the ALLRT cohort. AIDS (London, England). Jan 28;25 (3):357-65.

[282] Letendre SL, McCutchan JA, Childers ME, Woods SP, Lazzaretto D, Heaton RK, et al. Enhancing antiretroviral therapy for human immunodeficiency virus cognitive disorders. Ann Neurol. 2004 Sep;56 (3):416-23.

[283] Winston A, Duncombe C, Li PC, Gill JM, Kerr SJ, Puls R, et al. Does choice of combination antiretroviral therapy (cART) alter changes in cerebral function testing after 48 weeks in treatment-naive, HIV-1-infected individuals commencing cART? A randomized, controlled study. Clin Infect Dis. Mar 15;50 (6):920-9. 